\title{
Hydroxyl Radical as Key Intermediate in Curing Action of Artemisinin and its Analogs
}

Evgeny T Denisov* and Taisa G Denisova

Institute of Problems of Chemical Physics, RAS, Chernogolovka, Moscow Region, Russia

\begin{abstract}
A kinetic analysis of intramolecular oxidation reactions of 1 derivatives in combination with the published data on antimalarial activity makes it possible to formulate the following mechanism of action of the peroxide drugs, analogs of compound 1. Under the reaction of the Fe(II) chelates the compound containing the peroxide group is transformed into the alkoxyl radical. This radical isomerizes to the alkyl radical, which further undergoes intramolecular chain oxidation. This oxidation results in polyatomic hydroperoxides, which, in turn, generates radicals in the reaction with $\mathrm{Fe}(\mathrm{II})$. The next cascade of radical reactions generates very reactive hydroxyl radicals, whose sources are peroxyl radicals with hydroperoxide fragments and a-dihydroperoxides. The higher the yield of hydroxyl radicals $\mathrm{nOH}$, the more efficient the drug. The dependence of the antimalarial activity of the ith drug IC50(1)M(i)/IC50(i)M(1) on the yield of radicals $\mathrm{HO} n O H$ is nonlinear (exponential). The compounds with $\mathrm{nOH} \geq 3$ are efficient.
\end{abstract}

Keywords: Artemisinin; Derivatives; Free radicals; Hydroxyl; Oxidation; Hybrid; Isomerization

\section{Introduction}

Artemisinin [1] is a highly efficient drug, different modifications of which are successfully used against malaria plasmodium (Plasmodium falciparum) resistant to quinine and its analogs of the alkaloid type. The exited history of opening and study of compound $\mathbf{1}$ is described in a line of reviews [1-13] Structure 1 is a sesquiterpene endoperoxide. The curing effect of compound $\mathbf{1}$ was proved to be result of generation of free radicals $[1,2,5,14-20]$. The peroxide bridge in structure 1 generates free radical via the redox reaction with chelates of divalent iron

$\mathrm{ROOR}+\mathrm{Fe}^{2+} \rightarrow \mathrm{RO}^{\bullet}+\mathrm{RO}^{-}+\mathrm{Fe}^{3+}$, which, as it is believed, results in the death of the parasite. It was assumed for a long time that the mechanism of the antimalarial effect of compound $\mathbf{1}$ is reduced to this reaction, i.e., compound 1 "works" as a usual initiator [4-20]. However, the synthesis and testing of its analogs on antimalarial activity showed that the whole structure of molecule 1 rather than its peroxide bridge only plays an important role [1,2]. Using the kinetic analysis of the reactions occurring after the cleavage of the peroxide bridge in compound $\mathbf{1}$ in the presence of oxygen, it was proved that the free radicals formed are involved in a cascade of consecutive transformations with participation of oxygen [21-27]. As a result, compound $\mathbf{1}$ is transformed into polyatomic hydroperoxide. The latter generates a line of free radicals via the reaction with $\mathrm{Fe}(\mathrm{II})$, which results in the death of the parasite. It was evidenced in our latest kinetic studies that namely hydroxyl radical, produced in some reactions of $\mathbf{1}$ oxidation plays the key role in curing action of $\mathbf{1}$ and its peroxide analogs [28-31]. This paper summarizes the results received during the latest four years on kinetic analysis of reactions induced by $\mathbf{l}$ and its derivatives.

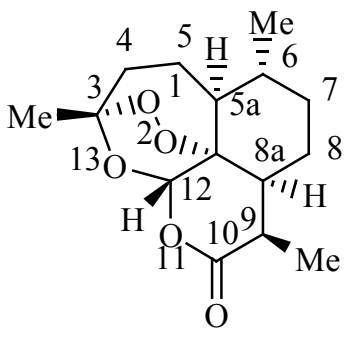

1

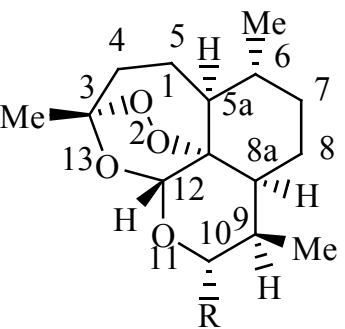

Derivatives of

10-dihydroartemisinin

\section{Intramolecular Oxidation of Artemisinin}

Under aerobic conditions in the living organism, cycloalkyl radicals derived from 1 add oxygen. The addition of $\mathrm{O}_{2}$ to alkyl radicals is limited only by the self-diffusion of oxygen and occurs with a high rate constant $\left(k_{\mathrm{O} 2}\right)$ of $10^{9} \div 10^{10}$ liter $\mathrm{mol}^{-1} \mathrm{~s}^{-1}$. In lipids, the constant $k_{\mathrm{O} 2}$ is similar to those in linoleic acid esters where it is equal to $k_{\mathrm{O} 2}=1.56$ $\times 10^{9}$ liter $\mathrm{mol}^{-1} \mathrm{~s}^{-1}$ [32]. The Henry coefficient of oxygen $\left(\gamma_{\mathrm{O} 2}\right)$ in this medium is $\gamma_{\mathrm{O} 2}=1.12 \times 10^{-2} \mathrm{~mol} \mathrm{liter}^{-1}$ atm $^{-1}$ [32]. Hence, the specific rate of the reaction of alkyl radicals with oxygen at $\mathrm{p}\left(\mathrm{O}_{2}\right)=0.21 \mathrm{~atm}$ (in air) is equal to $k_{\mathrm{O} 2} \gamma_{\mathrm{O} 2} p\left(\mathrm{O}_{2}\right)=3.56 \times 10^{6} \mathrm{~s}^{-1}$. A comparison of the oxygen addition with the monomolecular reactions of the artemisinin alkyl radicals as well as the reaction with L-cysteine showed that this reaction is the most rapid transformation channel for the majority of radicals [26,27]. Therefore, under aerobic conditions these are the following main reaction channels of radicals generated from peroxide bridge of artemisinin:

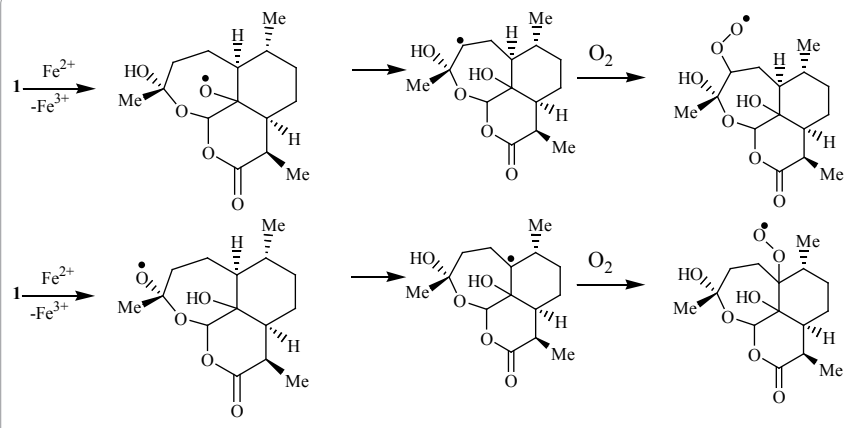

*Corresponding author: Evgeny $\mathrm{T}$ Denisov, Institute of Problems of Chemical Physics, RAS, Chernogolovka, Moscow Region, Russia, Tel: +7-496-522-10-82; Fax: +7-496-522-35-07; E-mail: det@icp.ac.ru

Received October 20, 2014; Accepted December 15, 2014; Published December 18,2014

Citation: Denisov ET, Denisova TG (2014) Hydroxyl Radical as Key Intermediate in Curing Action of Artemisinin and its Analogs. Med chem 4: 798-813. doi:10.4172/2161-0444.1000233

Copyright: (c) 2014 Denisov ET, et al. This is an open-access article distributed under the terms of the Creative Commons Attribution License, which permits unrestricted use, distribution, and reproduction in any medium, provided the original author and source are credited. 
Citation: Denisov ET, Denisova TG (2014) Hydroxyl Radical as Key Intermediate in Curing Action of Artemisinin and its Analogs. Med chem 4: 798813. doi:10.4172/2161-0444.1000233

The further transformations of the artemisinin peroxyl radicals were analyzed for the first time in the studies [24,25]. The formed peroxyl radical induces in $\mathbf{1}$ a cascade of intramolecular chain reactions with production of artemisinin with a line of hydroperoxide groups. Down are given examples of such reactions [25].
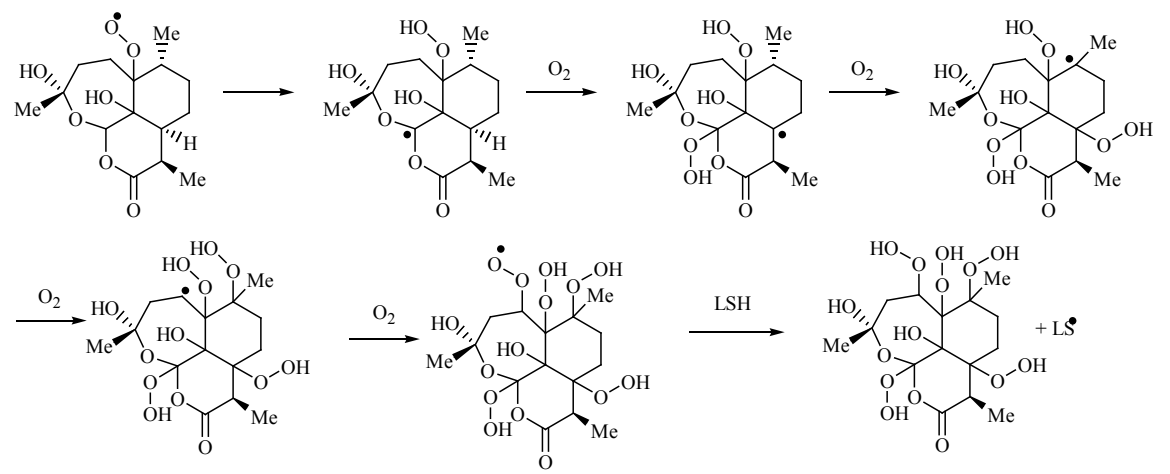

When the possibility of intramolecular chain reaction inside $\mathbf{1}$ is exhausted, peroxyl radical reacts with any substrate. Among them thio-groups of L-cysteine are the most reactive (Figure 1), and free valence abandons the molecule in the form of thiyl radical [25].

Peroxyl radicals participate not only in consecutive, but parallel reactions too. There are given in Table 1, the parameters for all parallel reactions of radical $\mathrm{C}^{8} \mathrm{OO}$.

The formed hydroperoxide groups are decomposed by Fe(II) into alkoxyl radicals that, in its turn, start a new cascade of oxidation reactions. The kinetic scheme of 1 oxidation is given dawn with kinetic characteristics of every limiting stage.

Each stage involving the peroxyl radical includes two consecutive elementary acts: the fast addition of oxygen to the alkyl radical and the intrinsic fast reaction involving $\mathrm{RO}_{2}$ - formed. This scheme shows that alkoxyl radical $\mathrm{RO} \cdot(1)$ formed from compound $\mathbf{1}$ isomerizes exclusively to alkyl radical $\mathrm{R}^{\cdot}(5 \mathrm{a})$. The single parallel reaction of $\mathrm{RO}^{\cdot}(2)$ with $\mathrm{LSH}$ is by three orders of magnitude slower $\left(k(\mathrm{LSH})=1.0 \times 10^{6} \mathrm{~s}^{-1}\right)$. As a result of a chain of successive radical transformations, $\mathrm{R} \cdot(5 \mathrm{a})$ generates four hydroxyl radicals. Since only $50 \%$ of the molecules reacted with Fe(II) generates

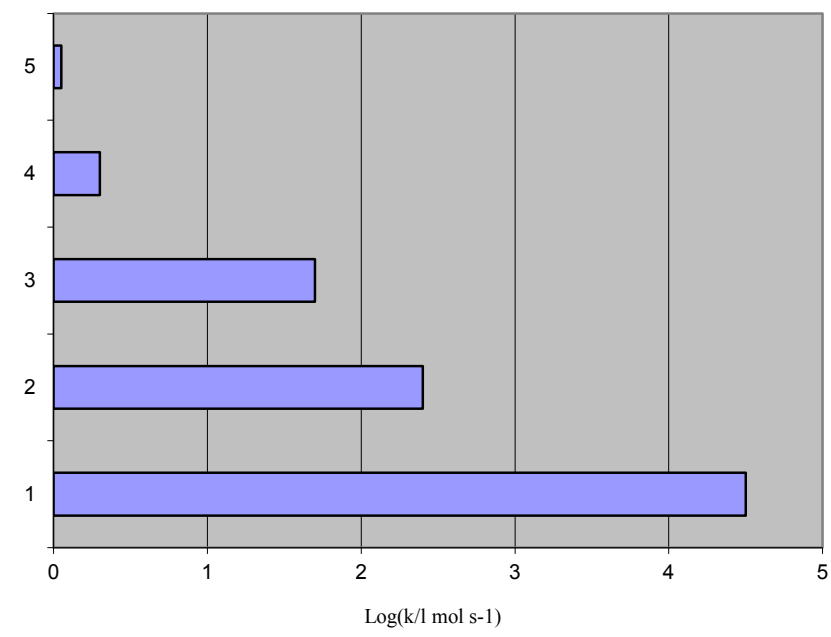

Figure 1: Rate constants $(T=310 \mathrm{~K})$ of peroxyl radical reactions with substrates: 1 - L-Cystein, 2 - Glucose, 3 - Methyllinoleate, 4 - Methyloleate, 5 - Glicerol [25]

\begin{tabular}{|c|c|c|c|c|}
\hline Reaction & $\begin{array}{c}\Delta H, \\
\mathrm{~kJ} / \mathrm{mol}\end{array}$ & $\begin{array}{c}E, \\
\mathrm{~kJ} / \mathrm{mol}\end{array}$ & $\begin{array}{c}\boldsymbol{k}(310 \mathrm{~K}) \\
\mathbf{s}^{-1}\end{array}$ & $\%$ \\
\hline $\mathrm{C}^{8 \mathrm{a} O \mathrm{OO}} \rightarrow \mathrm{C}^{12}$ & 19.9 & 44.6 & $1.71 \times 10^{5}$ & 62.6 \\
\hline $\mathrm{C}^{8 \mathrm{a} O \mathrm{OO}} \rightarrow \mathrm{C}^{8}(\mathrm{O})+\mathrm{HO} \cdot$ & -110.5 & 42.7 & $6.78 \times 10^{4}$ & 25.0 \\
\hline $\mathrm{C}^{8 \mathrm{a} O O} \cdot \rightarrow \mathrm{C}^{5 \mathrm{a}}$ & 31.7 & 50.3 & $1.81 \times 10^{4}$ & 6.4 \\
\hline $\mathrm{C}^{8 \mathrm{a} O \mathrm{OO}} \rightarrow \mathrm{C}^{10}$ & 34.4 & 51.7 & $1.07 \times 10^{4}$ & 4.0 \\
\hline $\mathrm{C}^{8 \mathrm{a} O O} \cdot \rightarrow \mathrm{C}^{6}$ & 38.2 & 53.6 & $5.12 \times 10^{3}$ & 1.8 \\
\hline 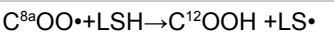 & 1.6 & 32.4 & $6.93 \times 10^{1}$ & 0.03 \\
\hline
\end{tabular}

Table 1: Kinetic parameters of parallel reactions of $\mathbf{C}^{\mathbf{8 a}}$ peroxyl radical of $\mathbf{1}$. 
Citation: Denisov ET, Denisova TG (2014) Hydroxyl Radical as Key Intermediate in Curing Action of Artemisinin and its Analogs. Med chem 4: 798813. doi:10.4172/2161-0444.1000233

radicals $\mathrm{RO}^{*}(2)$, the yield of radicals $\mathrm{HO}^{*}$ per molecule $\mathbf{1}$ via this radical is equal to 2 . The transformation of radical RO*(1) proceeds via two parallel channels. The total yield of radicals $\left(n_{\Sigma \mathrm{R}}\right)$ per one molecule of $\mathbf{1}$ is $n_{\Sigma \mathrm{R}}=4.34$, of which $n_{\mathrm{OH}}=3.17$ and $n_{\mathrm{LS}}=1.17$.

One can suppose that the more free radicals are produced by one molecule of drug curing by free radical generation, the more will be activity of antimalarial drug. A kinetic scheme of oxidation was built up for a line of 1 derivatives with the following structures [28-30]:

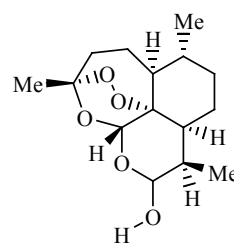

(2)

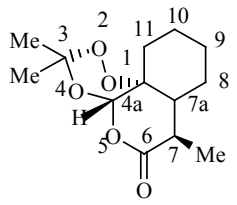

6

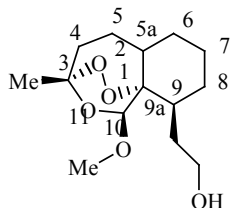

10

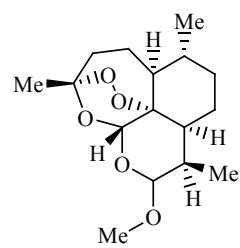

(3)

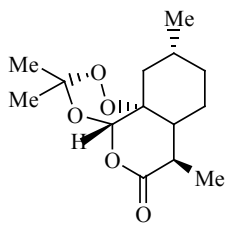

7<smiles>COC1O[C@H]2O[C@]1(C)CC1CCC[C@H](CCO)[C@H]12</smiles>

11

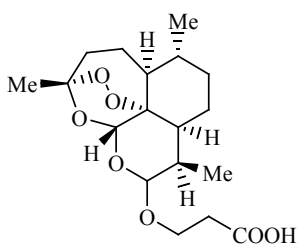

(4)

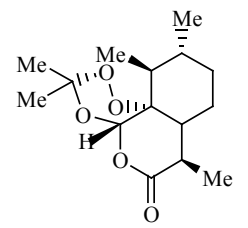

8

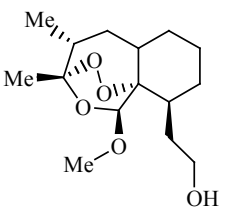

12

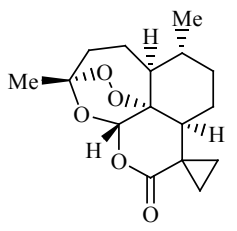

(5)

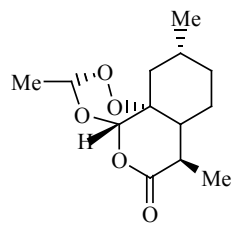

9

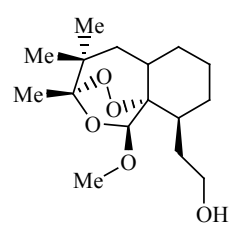

13

The total yield of free radicals $n_{\Sigma \mathrm{R}}$ was compared with values of relative indexes $\mathrm{IC}_{50}$ (Figure 2) [28-31].

The result appeared paradoxal: it is clearly seen that any correlation is absent. On the one hand, there are compounds with $n_{\Sigma \mathrm{R}}$ equal to 3.5 and 5 among highly efficient antimalarial drugs. On the other hand, the compound with $n_{\Sigma \mathrm{R}}=6$ turned out lowly efficient. Therefore, the high total yield of free radicals does not indicate that the drug is efficient.

\section{The Important role of Hydroxyl Radicals}

It is seen from scheme 1 that free radicals $\mathrm{R}^{*}, \mathrm{RO}^{*}$, and $\mathrm{RO}_{2}$, formed in the process of 1 oxidation, are transformed inside the oxidized molecule. Free valence abandons the molecule in the forms of thiyl or hydroxyl radicals. Thiyl radicals are formed in bimolecular reactions of $\mathrm{RO}^{*}$ or $\mathrm{RO}_{2}{ }^{\circ}$ radicals with thio-groups of L-cystein in polypeptides. They have low activity and recombine with resulting scission of polypeptides [32-37].

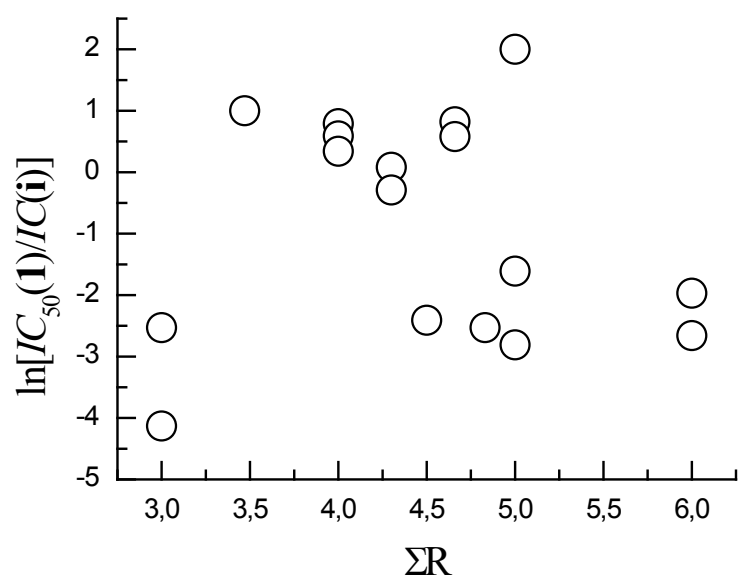

Figure 2: Correlation between logarithm of relative antimalarial activity $\ln \left\{\mathrm{IC}_{50}(\mathbf{1}) / \mathrm{IC}_{50}(\mathrm{i})\right\}$ of artemisinin derivatives $1-13$ and total number of free radicals $\Sigma \mathrm{R}$ produced in the result of their oxidation. 

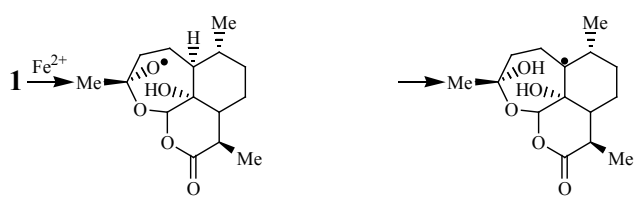

$$
\Delta H=-48.5 ; E=17.0
$$

$$
k=5.5 \times 10^{9}
$$

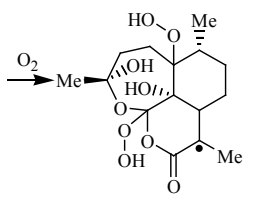

$$
\Delta H=32.4 ; E=52.6
$$$$
k=7.6 \times 10^{3}
$$

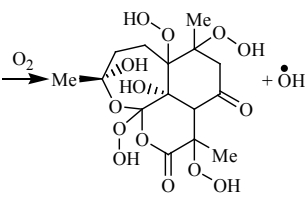

$$
\Delta H=17.2 ; E=43.2 \text {; }
$$$$
k=2.9 \times 10^{5}
$$
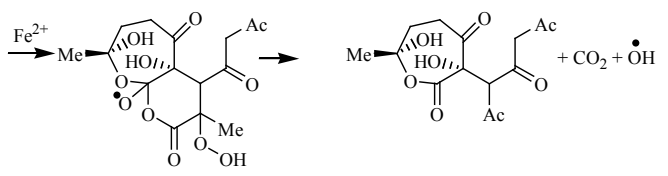

$$
k \approx 10^{12}
$$

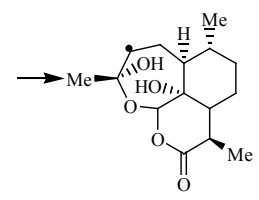

$$
\Delta H=-34.6 ; E=21.8 ;
$$$$
k=8.5 \times 10^{8}
$$$$
\stackrel{\mathrm{Me}}{\stackrel{\mathrm{Fe}^{2+}}{\longrightarrow}}
$$

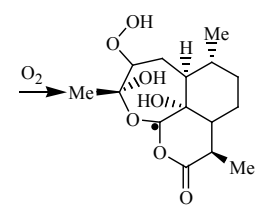

$$
\Delta H=12.6 ; E=42.7 \text {; }
$$$$
k=3.5 \times 10^{5}
$$

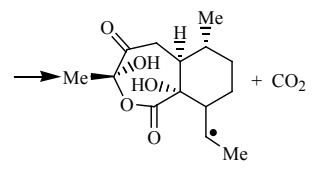

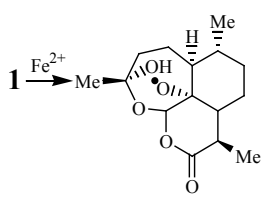

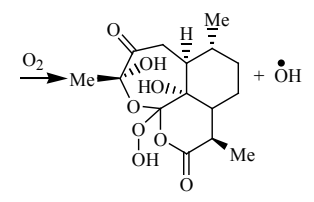

$$
\Delta H=-114.6 ; E=41.4 ;
$$

$$
k=1.2 \times 10^{5}
$$

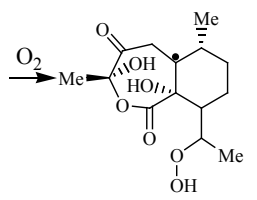

$$
\Delta H=24.5 ; E=46.7 \text {; }
$$$$
k=7.3 \times 10^{4}
$$
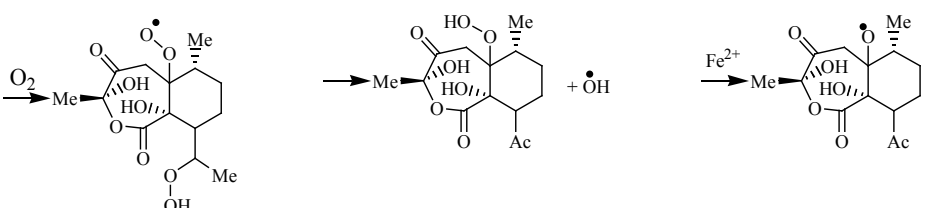

$\Delta H=-114.6 ; E=41.4 ;$ 

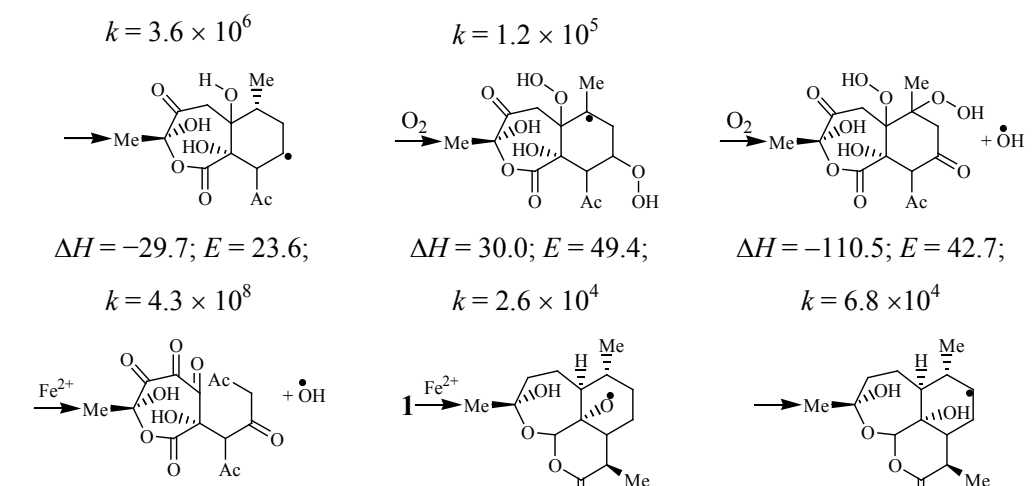

$$
\begin{gathered}
\Delta H=30.0 ; E=49.4 ; \\
k=2.6 \times 10^{4}
\end{gathered}
$$$$
\Delta H=-110.5 ; E=42.7 \text {; }
$$$$
k=6.8 \times 10^{4}
$$
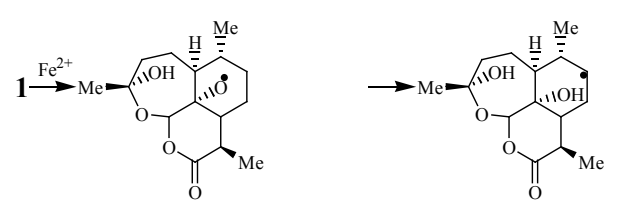

$$
\begin{gathered}
\Delta H=-29.7 ; E=23.6 ; \\
k=4.3 \times 10^{8}
\end{gathered}
$$
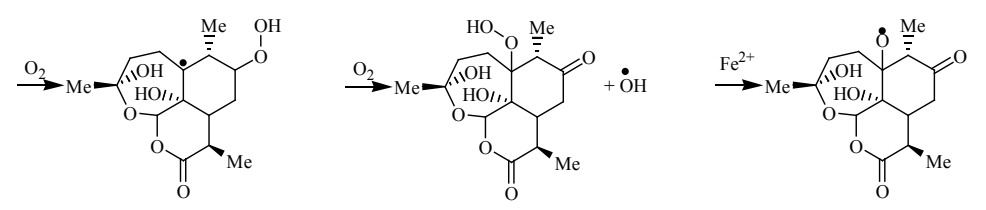

$$
\Delta H=24,5 ; E=46,7
$$

$$
k=7,3 \times 10^{4}
$$

$$
\Delta H=-110,5 ; E=42,7 \text {; }
$$
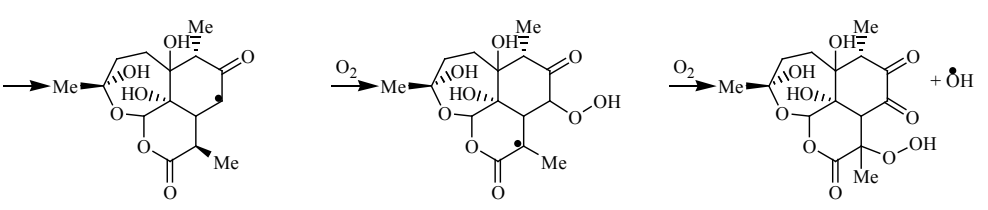

$$
\begin{array}{r}
\Delta H=-29.7 ; E=23.6 ; \\
k=4.3 \times 10^{8}
\end{array}
$$

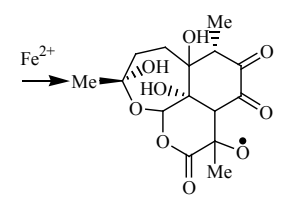

$\Delta H=25.3 ; E=48.7$;

$\Delta H=12.9 ; E=41.3$;

$$
k=3.4 \times 10^{4}
$$$$
k=6.0 \times 10^{5}
$$
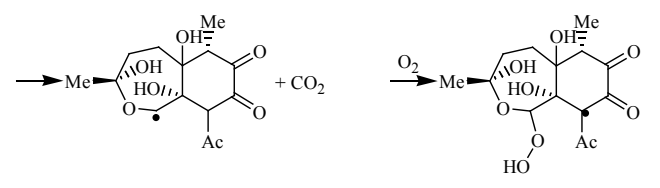

$$
k \approx 10^{12}
$$

$$
\Delta H=32.4 ; E=52.2 \text {; }
$$

$$
k=4.0 \times 10^{2}
$$
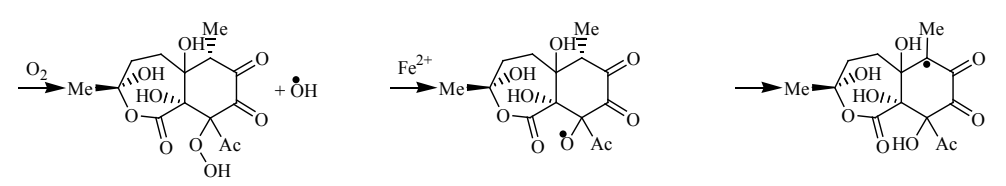

$$
\begin{gathered}
\Delta H=-114.0 ; E=41.4 ; \\
k=1.2 \times 10^{5}
\end{gathered}
$$
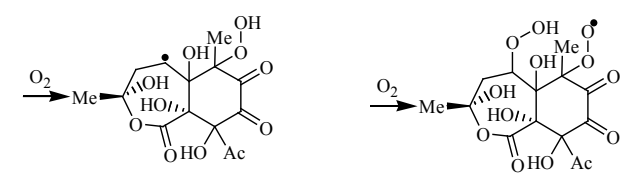

$$
\begin{gathered}
\Delta H=-43.0 ; E=18.8 ; \\
k=2.6 \times 10^{4}
\end{gathered}
$$

$$
\begin{gathered}
\Delta H=41.0 ; E=56.6 ; \\
k=1.6 \times 10^{3}
\end{gathered}
$$

$$
\begin{gathered}
\Delta H=-6.9 ; E=19.9 ; \\
k=1.5 \times 10^{8}
\end{gathered}
$$

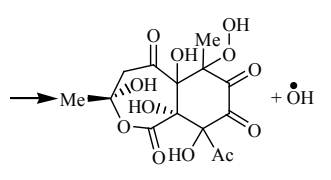

$$
\begin{gathered}
\Delta H=-114.6 ; E=41.4 ; \\
k=1.2 \times 10^{5}
\end{gathered}
$$



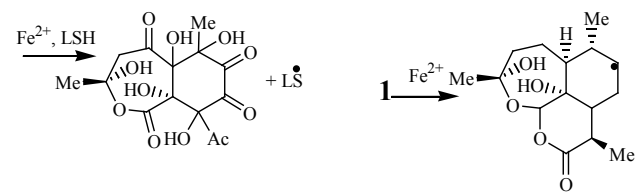

$$
\Delta H=-78.5 ; E=5.8
$$$$
k=2.1 \times 10^{6}
$$

$\Delta H=-29.7 ; E=23.6$;

$$
k=4.3 \times 10^{8}
$$

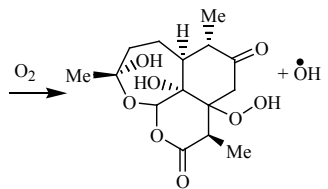

$\Delta H=-110.5 ; E=42.7$

$$
k=6.8 \times 10^{4}
$$

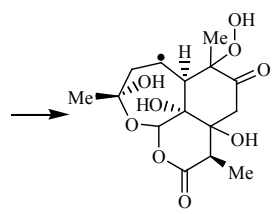

$$
\begin{gathered}
\Delta H=41.0 ; E=56.6 ; \\
k=1.6 \times 10^{3}
\end{gathered}
$$
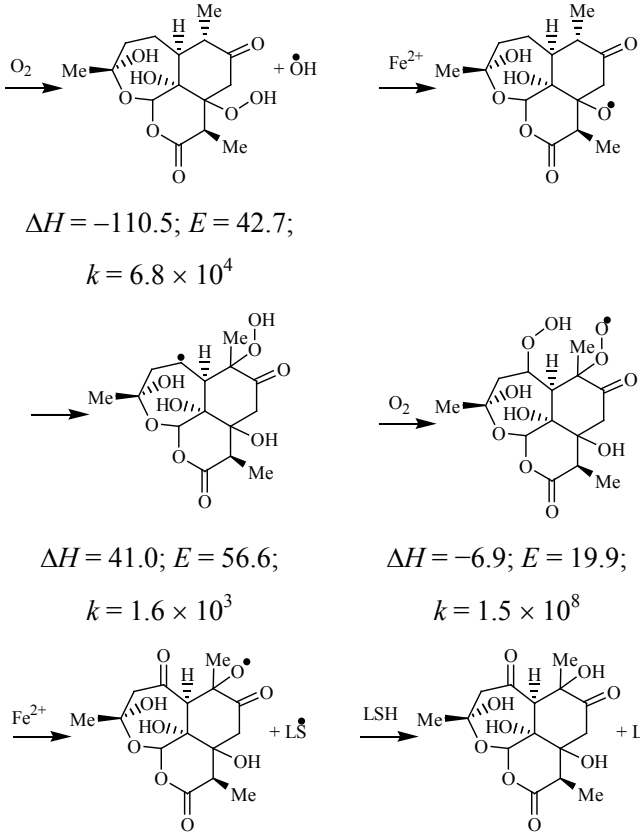

$\Delta H=-6.9 ; E=19.9$;

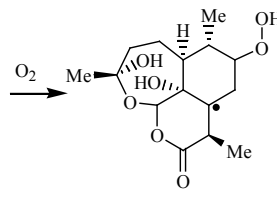

$\Delta H=22.1 ; E=45.8$;

$$
k=1.0 \times 10^{5}
$$

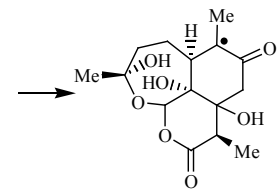

$$
\Delta H=-43.0 ; E=18.8 ;
$$

$$
k=2.6 \times 10^{4}
$$

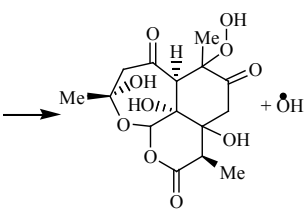

$\Delta H=-114.6 ; E=41.4 ;$ $k=1.2 \times 10^{5}$

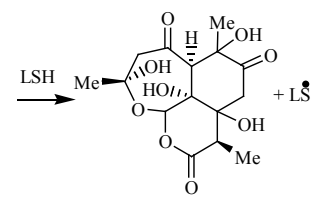

$$
\Delta H=-78.5 ; E=5.8
$$$$
k=2.1 \times 10^{6}
$$

Scheme 1: The mechanism of 1 oxidation; the values of enthalpies $(\Delta H, \mathrm{~kJ} / \mathrm{mol})$, activation energies $(E, \mathrm{~kJ} / \mathrm{mol})$ and rate constants $\left(k(310 \mathrm{~K}) \mathrm{s}^{-1}\right)$ were calculated by the method of intersecting parabolas: [32-34].

$\mathrm{RO}_{2} \cdot+\mathrm{LSH} \rightarrow \mathrm{ROOH}+\mathrm{LS} \cdot$

$\mathrm{RO}^{\bullet}+\mathrm{LSH} \rightarrow \mathrm{ROH}+\mathrm{LS}^{\bullet}$

$\mathrm{LS}^{\bullet}+\mathrm{LS} \cdot \mathrm{LSSL}$

Hydroxyl radicals are produced by isomerization of $\mathrm{RO}_{2} \cdot$ of the type:

$\mathrm{RCH}(\mathrm{OO} \cdot) \mathrm{CH}_{2} \mathrm{CH}(\mathrm{OOH}) \mathrm{R} \rightarrow \mathrm{RCH}(\mathrm{OOH}) \mathrm{CH}_{2} \mathrm{C}(\mathrm{O}) \mathrm{R}+\mathrm{HO}^{*}$

and in the result of decomposition of $\alpha$-dihydroperoxide:

$\mathrm{RCH}(\mathrm{OOH}) \mathrm{CH}(\mathrm{OOH}) \mathrm{R}+\mathrm{Fe}(\mathrm{II}) \rightarrow \mathrm{RCH}\left(\mathrm{O}^{*}\right) \mathrm{CH}(\mathrm{OOH}) \mathrm{R}+\mathrm{Fe}(\mathrm{III})+\mathrm{HO}^{-}$

$\mathrm{RCH}\left(\mathrm{O}^{*}\right) \mathrm{CH}(\mathrm{OOH}) \mathrm{R} \rightarrow \mathrm{RCH}(\mathrm{O})+\mathrm{RCH}(\mathrm{O})+\mathrm{HO}^{*}$.

Reactions of hydroxyl generation are extremely exothermic. For example, the reaction

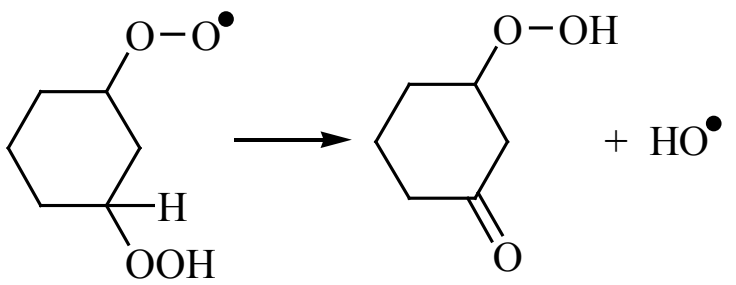


Citation: Denisov ET, Denisova TG (2014) Hydroxyl Radical as Key Intermediate in Curing Action of Artemisinin and its Analogs. Med chem 4: 798813. doi:10.4172/2161-0444.1000233

proceeds with enthalpy $\Delta H=-126 \mathrm{~kJ} / \mathrm{mol}$. Very exothermic is the reaction of decomposition of a-hydroperoxyalkoxyl radical formed from a-dihydroperoxide. For example, the reaction

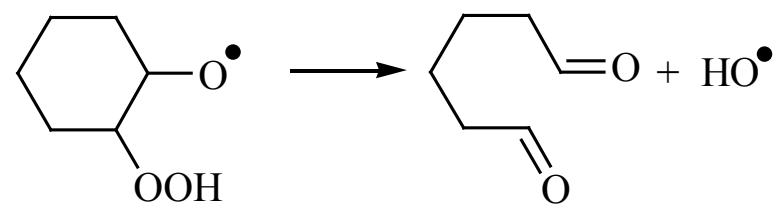

proceeds with $\Delta H=-137 \mathrm{~kJ} / \mathrm{mol}$.

The hydroxyl radicals due to high energy of formed $\mathrm{O}-\mathrm{H}$ bond $(\approx 500 \mathrm{~kJ} / \mathrm{mol})$ are extremely active in reactions of hydrogen atom abstraction. And we observe quite another situation when we compare $\mathrm{IC}_{50}$ with the relative yield of hydroxyl radicals by $\mathbf{1}$ derivatives (Table 2).

The results of comparison of $\ln \left\{M(\mathrm{i}) \mathrm{IC}_{50}(\mathbf{1}) / \mathrm{IC}_{50}(\mathrm{i}) M(\mathbf{1})\right\}$ and $n_{\mathrm{OH}}$ are presented on (Figure 3$)$. They indicate an explicit linear dependence between these values with a correlation coefficient of 0.97 and the root-mean-square deviation $\mathrm{SD}=0.5$ inside interval of $n_{\mathrm{OH}}=2.5 \div 4.0$.

This means that the curing effect of $\mathbf{1}$ derivatives is caused, first of all, by the generation of hydroxyl radicals that destroy malaria plasmodium. The dependence of $\ln \left\{M(\mathrm{i}) \mathrm{IC}_{50}(\mathbf{1}) / M(\mathbf{1}) \mathrm{IC}_{50}(\mathrm{i})\right\}$ on the yield of hydroxyl radicals is expressed by the following equation:

$\ln \left\{M(\mathbf{i}) \operatorname{IC}_{50}(\mathbf{1}) / M(\mathbf{1}) \mathrm{IC}_{50}(\mathbf{i})\right\}=3.9\left(n_{\mathrm{OH}}(\mathbf{i})-3.17\right)$

Drugs that are more active than compound 1 should provide the yield of hydroxyl radicals exceeding 3.17. The kinetic study of oxidation of dimers of 1 proved, however, that this dependence changes its character. When $n_{\mathrm{OH}}$ (i) of compound becomes more than 4, the dependence has the following form [38]:

\begin{tabular}{|c|c|c|c|c|c|}
\hline Compound & $n_{\mathrm{OH}}$ & $N_{\text {ER }}$ & $I C_{50}(1) / / C_{50}(\mathrm{i})$ & $\ln \left[I C_{50}(1) / I C_{50}(i)\right]$ & Ref. \\
\hline 1 & 3.17 & 4.00 & 1.00 & 0.00 & 35 \\
\hline 2 & 4.00 & 4.50 & 7.40 & 2.00 & 35 \\
\hline 3 & 3.83 & 4.66 & 2.28 & 0.82 & 35 \\
\hline 4 & 3.83 & 4.66 & 1.78 & 0.58 & 35 \\
\hline 5 & 1.67 & 4.33 & 0.08 & -2.53 & 35 \\
\hline 6 & 3.00 & 5.00 & 0.20 & -1.61 & 36 \\
\hline 7 & 3.30 & 4.30 & $1.08 ; 0.75^{*}$ & $0.08 ;-0.29$ & 36 \\
\hline 8 & 3.00 & 6.00 & 0.14 & -1.97 & 36 \\
\hline 9 & 0.50 & 1.00 & $0.00 ; 0.00$ * & - & 36 \\
\hline 10 & 2.83 & 4.50 & 0.09 & -2.41 & 37 \\
\hline 11 & 3.50 & 4.00 & $2.20 ; 1.80 ; 1.40$ * & $0.79 ; 0.59 ; 0.34$ & 37 \\
\hline 12 & 2.50 & 3.00 & 0.016 & -4.13 & 37 \\
\hline 13 & 2.50 & 3.00 & 0.016 & -4.13 & 37 \\
\hline
\end{tabular}

Table 2: Comparison of the antimalarial activity of compound 1 and its analogs (2-13) [35-37] with the number of hydroxyl radicals $n_{\mathrm{OH}}$, which are formed due to their intramolecular oxidation [28-31].

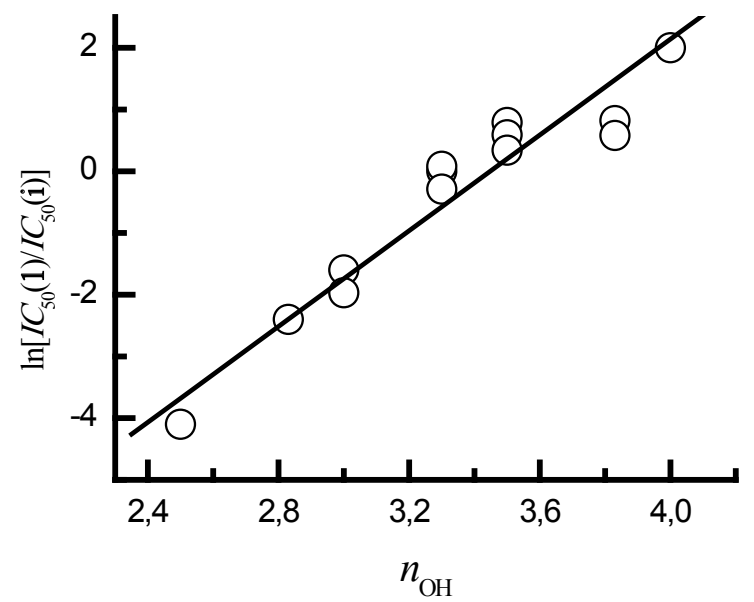

Figure 3: Correlation of relative antimalarial activity $\ln \left\{\mathrm{IC}_{50}(1) / I C_{50}(\mathrm{i})\right\}$ with the yield of hydroxyl radicals at oxidation of artemisinin derivatives. 
Citation: Denisov ET, Denisova TG (2014) Hydroxyl Radical as Key Intermediate in Curing Action of Artemisinin and its Analogs. Med chem 4: 798813. doi:10.4172/2161-0444.1000233

$M(\mathbf{i}) \mathrm{IC}_{50}(\mathbf{1}) / M(\mathbf{1}) \mathrm{IC}_{50}(\mathbf{i})=1+0.27\left(n_{\mathrm{OH}}(\mathrm{i})-3.17\right)$

Why do precisely the hydroxyl radicals cause the death of the malaria parasite? They are very reactive due to the high exothermicity of radical abstraction reactions involving these radicals. This is seen from the comparison of the $\mathrm{O}-\mathrm{H}$ bond strength in various compounds [39].

Compound / ( $\left.D_{\mathrm{O}-\mathrm{H}}, \mathrm{kJ} \mathrm{mol}{ }^{-1}\right)$ sec-ROOH(365.5), PhO-H(369.0), MeO-H(436.0), HO-H(499.0)

For this reason, hydroxyl radical reacts with many reactants with a huge rate constant and is poorly selective. The reaction of hydroxyl addition is also very fast. In particular, it reacts with organic bases composing DNA with diffusion rate constant. The values of $k\left(\mathrm{HO}^{*}+\mathrm{base}^{*}\right.$ in $\mathrm{H}_{2} \mathrm{O}$ are presented below [40].

Base / $\left(k \times 10^{-9} / \mathrm{l} \mathrm{mol}^{-1} \mathrm{~s}^{-1}, 298 \mathrm{~K}\right)$ Adenine (5.5, $\left.\mathrm{pH}=5.7\right)$, Guanine (5.8, $\left.\mathrm{pH}=10.0\right)$, Thymine (5.8, $\left.\mathrm{pH}=6.0\right), \mathrm{Cytosine}(9.2, \mathrm{pH}=7.0)$

So, it is likely that it is the DNA of malaria plasmodium that is the biological target, whose reaction with HO radicals results in the death of the parasite. It was experimentally shown that in the presence of iron ions of compound $\mathbf{1}$ caused the destruction of DNA plasmodium [1,41,42]. Another biological target of hydroxyl radical may be catalytic Fe-centers of enzymes that plays important role in parasite life [6].

\section{Cyclohexyl Endoperoxides}

The cyclohexyl endoperoxides are known as potential antimalarials. The following compounds 14-28 were sinthesised and tested on antimalarial activity by M. P. Crespo et al. [43] .

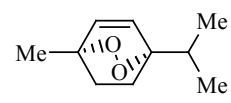

14

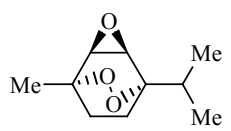

18

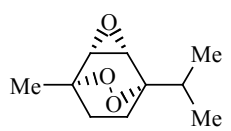

22

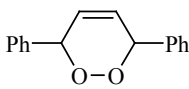

26

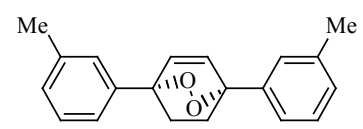

15

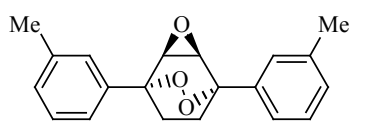

19

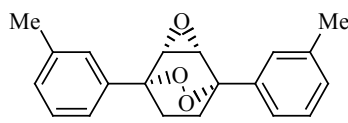

23

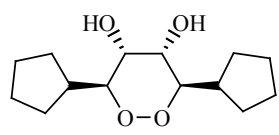

27

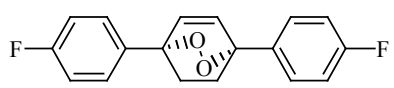

16

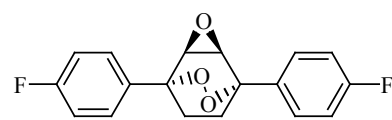

20

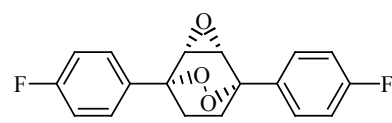

24

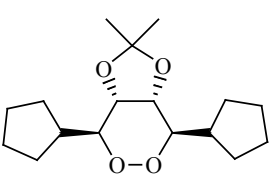

28

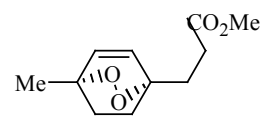

17

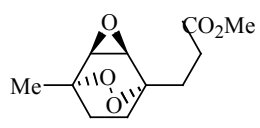

21

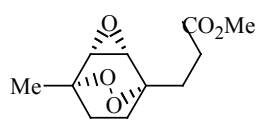

25

The kinetic scheme of free radical reactions of endoperoxides 14-17 is presented below.

Since the substituents $\mathrm{R}$ in the third and sixth positions are uninvolved in the free radical reactions, this scheme is the same for all of the four compounds (14-17). Alkoxyl radicals result from the decomposition of an endoperoxide by a Fe(II) chelate. They isomerizes rapidly into alkyl radicals, and the latter turn rapidly into peroxyl radicals in the presence of oxygen [32]. All parallel reactions were considered for each reaction step, and the most rapid of them are included in Scheme 2. In the cases in which the rate constants of two parallel reactions are comparable (their ratio is no larger than 5), were taken into account. The results of comparison of the molar effectiveness of the endoperoxides $M(\mathrm{i}) I_{50}(\mathbf{1}) / M(\mathbf{1}) I C_{50}(\mathrm{i}) \mathrm{with}$ total yield of free radicals $n_{\Sigma \mathrm{R}}$ are presented in (Table 3 ).

Clearly, peroxides characterized by the same free radical yield differ in their antimalarial effectiveness. Averaging of the $M(\mathbf{1}) \mathrm{IC}_{50}(\mathrm{i}) / M(\mathrm{i}) \mathrm{IC}_{50}(\mathbf{1})$ values yielded the following results:

\begin{tabular}{|c|c|c|c|}
\hline Endoperoxides & $\mathbf{1 4 - 1 7}$ & $\mathbf{1 8 - 2 6}$ & 2.0 \\
\hline$n_{\Sigma \mathrm{R}}$ & 1.0 & 2.68 \\
\hline$M(\mathbf{1}) \mathrm{IC}_{50}(\mathrm{i}) / M(\mathrm{i}) \mathrm{IC}_{50}(\mathbf{1})$ & $2.3 \times 10^{-3}$ & $2.3 \times 10^{-2}$ & $3.3 \times 10^{-2}$ \\
\hline
\end{tabular}

The antimalarial effectiveness of the peroxides depends linearly on the total radical yield $n_{\Sigma \mathrm{R}}$ and can be fitted to the linear equation (3).

$\mathrm{IC}_{50}(\mathbf{1}) M(\mathrm{i}) / \mathrm{IC}_{50}(\mathrm{i}) M(\mathbf{1})=(1.85 \pm 0.16) \times 10^{-2}\left(n_{\Sigma \mathrm{R}}-0.84\right)$

Thus, the antimalarial activity of the monocyclic endoperoxides increases with an increasing total free radical yield per unit amount of peroxide 


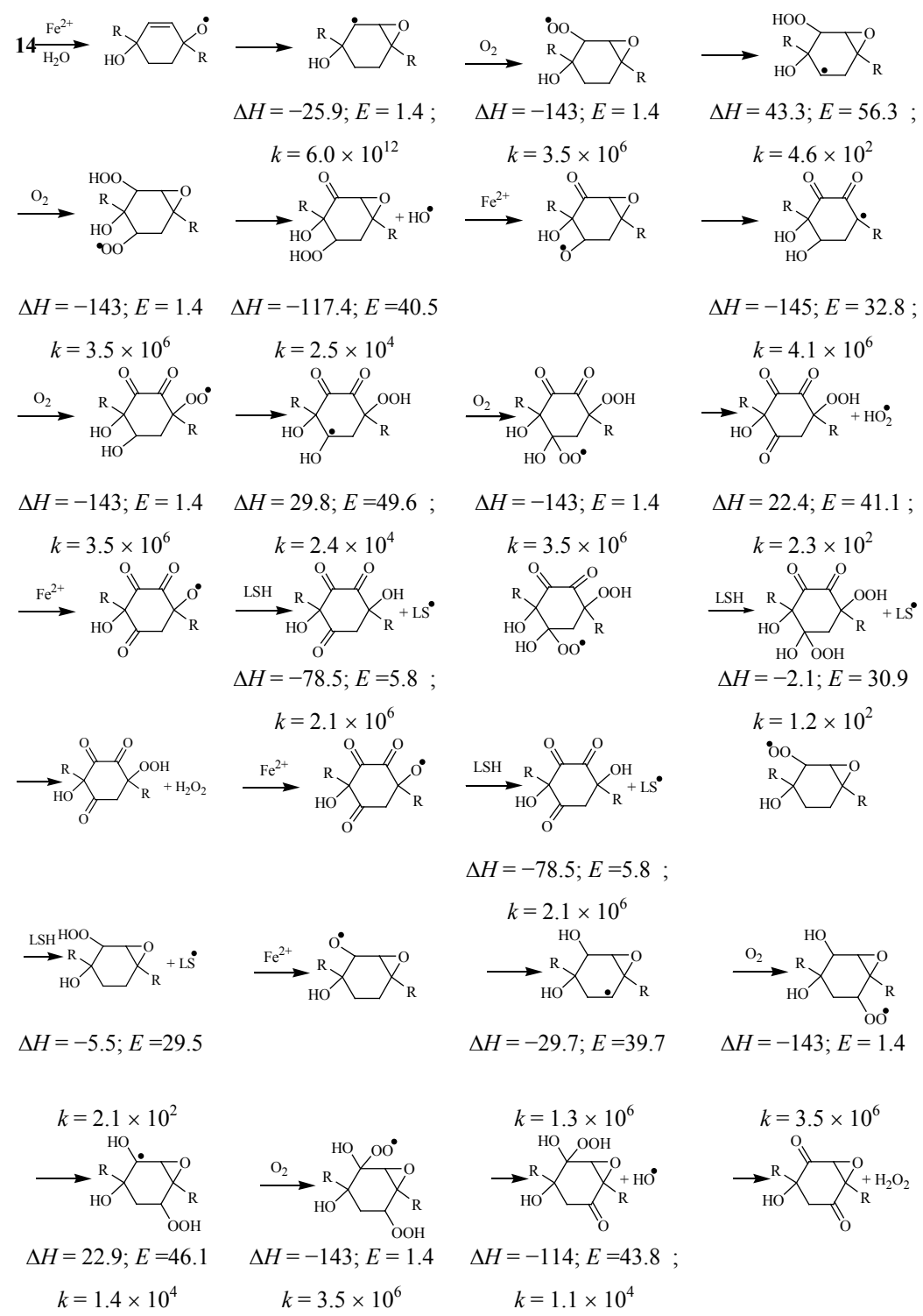

Scheme 2: The mechanism of oxidation of 14 [43]; the values of enthalpies $(\Delta H, \mathrm{~kJ} / \mathrm{mol})$, activation energies $(E, \mathrm{~kJ} / \mathrm{mol})$ and rate constants $\left(k(310 \mathrm{~K}) \mathrm{s}^{-1}\right) \mathrm{were}$ calculated by the method of intersecting parabolas: [32-34].

\begin{tabular}{|c|c|c|c|c|c|c|}
\hline \multirow[t]{2}{*}{$\mathbf{N}$} & \multirow[t]{2}{*}{$\boldsymbol{n}_{\text {но }}$} & \multirow[t]{2}{*}{$n_{\mathrm{HO} 2}$} & \multirow[t]{2}{*}{$n_{\text {LS }}$} & \multirow[t]{2}{*}{$n_{\Sigma R}$} & \multicolumn{2}{|c|}{$M(1) I C_{50}(\mathrm{i}) / M(\mathrm{i}) I \mathrm{C}_{50}(1)$} \\
\hline & & & & & Clone D10 & Clone K1 \\
\hline 14 & 1.00 & 0.45 & 1.24 & 2.69 & $2.1 \times 10^{-2}$ & $4.4 \times 10^{-2}$ \\
\hline 15 & 1.00 & 0.45 & 1.24 & 2.69 & $1.7 \times 10^{-2}$ & - \\
\hline 16 & 1.00 & 0.45 & 1.24 & 2.69 & $4.8 \times 10^{-2}$ & $5.1 \times 10^{-2}$ \\
\hline 17 & 1.00 & 0.45 & 1.24 & 2.69 & $1.9 \times 10^{-3}$ & - \\
\hline 18 & 0 & 0 & 2 & 2.00 & $2.9 \times 10^{-2}$ & $6.0 \times 10^{-2}$ \\
\hline 19 & 0 & 0 & 2 & 2.00 & $5.7 \times 10^{-2}$ & $3.1 \times 10^{-2}$ \\
\hline 20 & 0 & 0 & 2 & 2.00 & $1.5 \times 10^{-1}$ & $1.6 \times 10^{-1}$ \\
\hline 21 & 0 & 0 & 2 & 2.00 & $7.3 \times 10^{-3}$ & - \\
\hline 22 & 0 & 0 & 2 & 2.00 & $1.1 \times 10^{-2}$ & $1.9 \times 10^{-2}$ \\
\hline 23 & 0 & 0 & 2 & 2.00 & $7.2 \times 10^{-3}$ & - \\
\hline 24 & 0 & 0 & 2 & 2.00 & $4.0 \times 10^{-2}$ & $7.7 \times 10^{-2}$ \\
\hline 25 & 0 & 0 & 2 & 2.00 & $1.5 \times 10^{-3}$ & - \\
\hline 26 & 0 & 0 & 2 & 2.00 & $1.110^{-3}$ & $8.4 \times 10^{-3}$ \\
\hline 27 & 0 & 0.40 & 0.60 & 1.00 & $2.4 \times 10^{-3}$ & - \\
\hline 28 & 0 & 0.40 & 0.60 & 1.00 & $2.2 \times 10^{-3}$ & - \\
\hline
\end{tabular}

Table 3: Comparison of the antimalarial activity of endoperoxides $\mathbf{1 4 - 2 8}\left(M(1) I C_{50}(i) / M(i) I C_{50}(1)\right)[43]$ with the number of free radicals, which are formed due to their intramolecular oxidation [44]. 
decomposed. The $\mathrm{IC}_{50}(\mathbf{1}) M(\mathrm{i}) / \mathrm{IC}_{50}(\mathrm{i}) M(\mathbf{1})$ ratio is a linear function of the total free radical yield. The peroxides characterized by $n \Sigma \mathrm{R} \leq 1$ show almost no antimalarial activity. The above empirical relationship between the antimalarial effectiveness and $n_{\Sigma R}$ provides an explanation for the fact that the linear peroxides ROOR and $\mathrm{ROOH}$ are inactive against malaria [1]. The activity of the monocyclic endoperoxides is only $0.2-3 \%$ of the activity of $\mathbf{1}$. The results reported here will augment insight into the correlation between free radical generation and the antimalarial action of peroxide drugs. We will now compare the structural and kinetic characteristics of monocyclic peroxide drugs to those of polycyclic ones, to which artemisinin derivatives belong.

\begin{tabular}{|c|c|}
\hline Cyclohexyl endoperoxides (14-28) & Artemisinin and its derivatives (1-13) \\
\hline Monocyclic structure. & Polycyclic structure. \\
\hline $\begin{array}{l}\text { Domination of the } \mathrm{RO}_{2}^{\cdot}+\mathrm{LSH} \rightarrow \mathrm{ROOH}+\mathrm{LS}^{\cdot} \text { reaction because of the } \\
\text { low rate of the } \mathrm{RO}_{2}^{\cdot} \rightarrow \mathrm{R}^{\cdot} \text { reaction in the linear radical. }\end{array}$ & $\begin{array}{l}\text { Domination of the } \mathrm{RO}_{2} \cdot \rightarrow \mathrm{R} \cdot \text { reaction because of the high reaction rate } \\
\text { in the cyclic radical. }\end{array}$ \\
\hline Short intramolecular oxidation chain (1 or 2 steps). & Long intramolecular oxidation chain ( $2-6$ steps). \\
\hline Free radical yield of 1 to 3 . & Free radical yield of up to 6 \\
\hline One or $2 \mathrm{OOH}$ groups formed. & Up to six $\mathrm{OOH}$ groups formed. \\
\hline $\mathrm{HO} \cdot$ yield of 0 to 1 & $\mathrm{HO} \cdot$ yield of 2 to 4 \\
\hline Linear dependence of $\mathrm{IC}_{50}$ on $n_{\Sigma \mathrm{R}}$. & Exponential dependence of $\mathrm{IC}_{50}$ on $n_{\mathrm{OH}}$. \\
\hline Relative antimalarial activity of $0-3 \%$. & Relative antimalarial activity of $20-200 \%$. \\
\hline
\end{tabular}

Clearly, the great difference in initiation behavior and therapeutic action between the monocyclic and polycyclic peroxides is due to the fact that the radicals of the former undergo comparatively slow intramolecular oxidation, while the radicals of the latter do this rapidly. The isomerization reaction $\mathrm{R}^{\cdot}$ in the cyclic structure is accompanied by a slight decrease in entropy and, as a consequence, is characterized by a large pre-exponential factor of $A=1.4 \times 10^{12} \mathrm{~s}^{-1}$. Monocyclic alkoxyl radical often decompose to yield linear radicals. The radicals forming from the latter isomerize at a low rate because of the high negative activation entropy (for these reactions, $A=2.0 \times 10^{9} \mathrm{~s}^{-1}$ ). As a consequence, the linear peroxyl radicals more readily enter into the bimolecular reaction:

$$
\mathrm{RO}_{2} \cdot+\mathrm{LSH} \rightarrow \mathrm{ROOH}+\mathrm{LS}
$$

so the peroxide does not turn into a polyatomic hydroperoxide, and this has adverse implications for its therapeutic action. The results of this study supplement earlier data concerning free radicals of $\mathbf{1}$ and its derivatives. The antimalarial activity of the endoperoxides is mainly determined by two factors. The major factor is generation of hydroxyl radicals by the polyatomic hydroperoxides that result from the chain intramolecular oxidation of the drug. The higher the HO yield, the higher the antimalarial activity of the compound. The $\mathrm{IC}_{50}$ value depends on $n_{\mathrm{OH}}$ in an exponential way (Equation 1). The other, less significant factor is generation of other radicals (RO*), which also kill the plasmodium, but do this less effectively. In terms of $\mathrm{IC}_{50}$, these radicals are 1-2 orders of magnitude less effective than the hydroxyl radicals. The $\mathrm{IC}_{50}$ value depends linearly on $n_{\Sigma \mathrm{R}}$. The peroxides generating a single radical are practically inactive against the plasmodium.

\section{Dispiro-1,2,4-trioxolanes}

Some of dispiro-1,2,4-trioxolanes with various structures show high antimalarial activity, while others are less active [35,44,45]. A kinetic analysis of their radical transformations seems important for theoretically describing the therapeutic action of this new class of antimalarial drugs. This analysis was undertaken for to find answers to the following questions [46]. Is the therapeutic action of dispiro-1,2,4-trioxolanes related to their ability to initiate radicals? What is the role of hydroxyl radicals in this initiation? What is the relationship between the initiating ability of 1,2,4-trioxolanes and their structure? The structure of 7 dispiro-1,2,4-trioxolanes, whose radical transformations were analyzed [35,45], are given below:

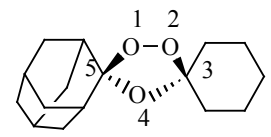

29

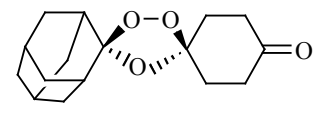

30

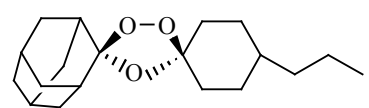

32

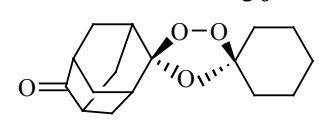

33

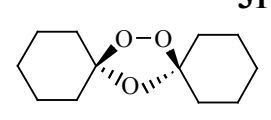

34

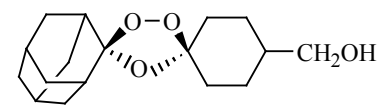

31

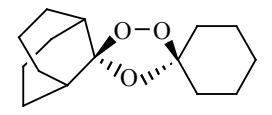

35

The scheme of free radical reactions of endoperoxides 29-32 oxidation (the same for all these compounds) is presented below.

As was noted earlier, for $\mathbf{1}$ and its derivatives, hydroxyl radicals were shown to be most active. This also follows from a comparison of the molar antimalarial activity of dispiro-1,2,4-trioxolanes considered here with the yield of hydroxyl radicals $n_{\mathrm{OH}}$ (Table 4).

Drugs 29-32 generate more hydroxyl radicals than $\mathbf{1}$ does and are therefore more active. Trioxolane 33 generates less hydroxyl radicals than $\mathbf{1}$ does (2.58 vs 3.17), and its antimalarial index being smaller (0.3) than that of $\mathbf{1}$. Trioxolanes $\mathbf{3 4}$ and $\mathbf{3 5}$ generate only thiyl radicals, and therefore 
Citation: Denisov ET, Denisova TG (2014) Hydroxyl Radical as Key Intermediate in Curing Action of Artemisinin and its Analogs. Med chem 4: 798813. doi:10.4172/2161-0444.1000233

\begin{tabular}{|c|c|c|c|c|}
\hline Compound & $n_{\mathrm{OH}}$ & $n_{\mathrm{LS}}$ & $\Sigma n$ & $M(\mathrm{i}) \mid \mathrm{C}_{50}(1) / M(1) I \mathrm{C}_{50}(\mathrm{i})$ \\
\hline 1 & 3.30 & 0.17 & 3.47 & 1.0 \\
\hline 29 & 3.41 & 1.35 & 4.76 & $1.5(1.54)$ \\
\hline 30 & 3.41 & 1.35 & 4.76 & 3.3 \\
\hline 31 & 3.41 & 1.35 & 4.76 & 2.2 \\
\hline 32 & 3.41 & 1.35 & 4.76 & 1.6 \\
\hline 33 & 2.58 & 1.84 & 4.42 & $0.3(0.06)$ \\
\hline 34 & 0.0 & 2.0 & 2.0 & $0.02(0.02)$ \\
\hline 35 & 0.0 & 2.0 & 2.0 & $0.02(0.02)$ \\
\hline
\end{tabular}

Table 4: Comparison of the antimalarial activity of dispiro-1,2,4-trioxalanes $29-35$ [35,45] with the number of free radicals, which are formed due to their intramolecula oxidation [46].

their antimalarial index being two orders of magnitude smaller than that of $\mathbf{1}$. For $\mathbf{1}$ and its derivatives, the empirical relationship between $\mathrm{IC}_{50}$ and $n_{\mathrm{OH}}$ is exponential (see Equation 1). According to this equation, $\mathrm{IC}_{50}(\mathbf{1}) M(\mathrm{i}) / \mathrm{IC}_{50}(\mathrm{i}) M(\mathbf{1})=2.52$ for $n_{\mathrm{OH}}=3.41$. This closely coincides with its mean value $2.15 \pm 0.70$ for trioxolanes 29-32. Trioxolanes $\mathbf{3 4}$ and $\mathbf{3 5}$ have a weak antimalarial activity (Table 4 ). Our analysis of the transformations of endoperoxides showed that the generation of only thiyl radicals also led to the antimalarial activity of the peroxide drug and the empirical relationship between $M(\mathrm{i}) \mathrm{IC}_{50}(\mathbf{1}) / M(\mathbf{1}) \mathrm{IC}_{50}(\mathrm{i})$ and $n_{\mathrm{LS}}$ was linear (see Equation 3). For $n_{\mathrm{LS}}=2\left(\operatorname{compounds} 33\right.$ and 34), IC $\mathrm{C}_{50}(\mathbf{1}) M(\mathrm{i}) / \mathrm{IC}$ (i) $M(\mathbf{1})=$ 0.02 , which coincides with the empirical results for dispiro-1,2,4-trioxolanes (Table 3). The mechanism of the therapeutical activity of dispiro-1,2,4trioxolanes containing a peroxide bridge is thus similar to that of $\mathbf{1}$ and its derivatives. Among the radicals formed by the oxidation of dispiro-1,2,4trioxolanes, only hydroxyl radicals exhibit a unique antimalarial activity. They are formed from dispiro-1,2,4-trioxolanes, which generate cyclic alkyl radicals during the decomposition of alkoxyl radicals. The oxidation of the former radicals gives rise to secondary hydroperoxide groups, whose subsequent radical transformation generates hydroxyl radicals. This is possible only in the case of dispiro-1,2,4-trioxolanes with polycyclic substituents (compounds 29-32). Decyclization of primary alkoxyl radicals formed from monocyclic dispiro-1,2,4-trioxolanes results in the transformation of the latter into linear peroxyl radicals. Isomerization of the latter, forming $>\mathrm{CHOOH}$ groups, becomes rather slow, the reaction of with the protein thio-groups being faster. The generation of hydroxyl radicals thus becomes impossible. The thiyl radicals formed by the reactions of RO ${ }^{*}$ and with LSH also show antimalarial activity. This is explained by the cross-linking of protein molecules [1,27]. This effect on the parasite organism is evidently much weaker than that of the reaction of hydroxyl radicals.

\section{Hybrid Analogs of 10-dihydroartemisinin}

Recently, synthesis and application of so called hybrid antimalarial agents are being developed, which comprise both the structure $\mathbf{1}$ with a peroxide bridge and fragments of the quininelike alkaloids [47]. However, when these agents are evaluated as hybrid ones an important aspect is omitted. When the structure of the compound of $\mathbf{3}$ type is changed, it has an effect on the course of radical reactions, and, as a consequence, on its antimalarial properties. Higher effectiveness of the compound of this type may result both from the additional pathway involving the introduced fragment into nonradical mechanism and from the higher outcome of hydroxyl radicals formed in its radical transformation. This is why the hybrid action of antimalarial substances of this type cannot be evaluated by simple comparison of its effectiveness with that of compounds 1 or 3 . The aim of the work [48] was to study the effect of additional residues incorporated into the molecule $\mathbf{3}$ on the ability to generate hydroxyl radicals and to evaluate its possible influence on the antimalarial substance by another (nonradical) mechanism. For this purpose a special approach was elaborated and the kinetic study of the radical transformations was accomplished for a series of eleven hybrid compounds, which were synthesized and tested for antimalarial activity earlier [47].

$$
\mathrm{R}=\mathrm{OCH}_{3}(\mathbf{3 6})
$$<smiles>COCc1ccc(CN2CCN(c3ccccc3)CC2)cc1</smiles><smiles>COCc1ccc(CN2CCN(c3ccc(F)cc3)CC2)cc1</smiles><smiles>COCc1ccc(CN2CCN(c3ccc(C(F)(F)F)cc3)CC2)cc1</smiles><smiles>COCc1ccc(CN2CCN(Cc3ccccc3)CC2)cc1</smiles><smiles>COCc1cccc(CN2CCN(c3ccccc3)CC2)c1</smiles><smiles>COCc1cccc(CN2CCN(c3ccc([N+](=O)[O-])cc3)CC2)c1</smiles><smiles>COCc1cccc(CN2CCN(c3ccc(Cl)cc3)CC2)c1</smiles><smiles>COCc1cccc(CN2CCN(c3cccc(C(F)(F)F)c3)CC2)c1</smiles>

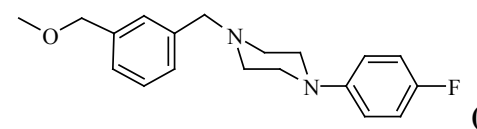




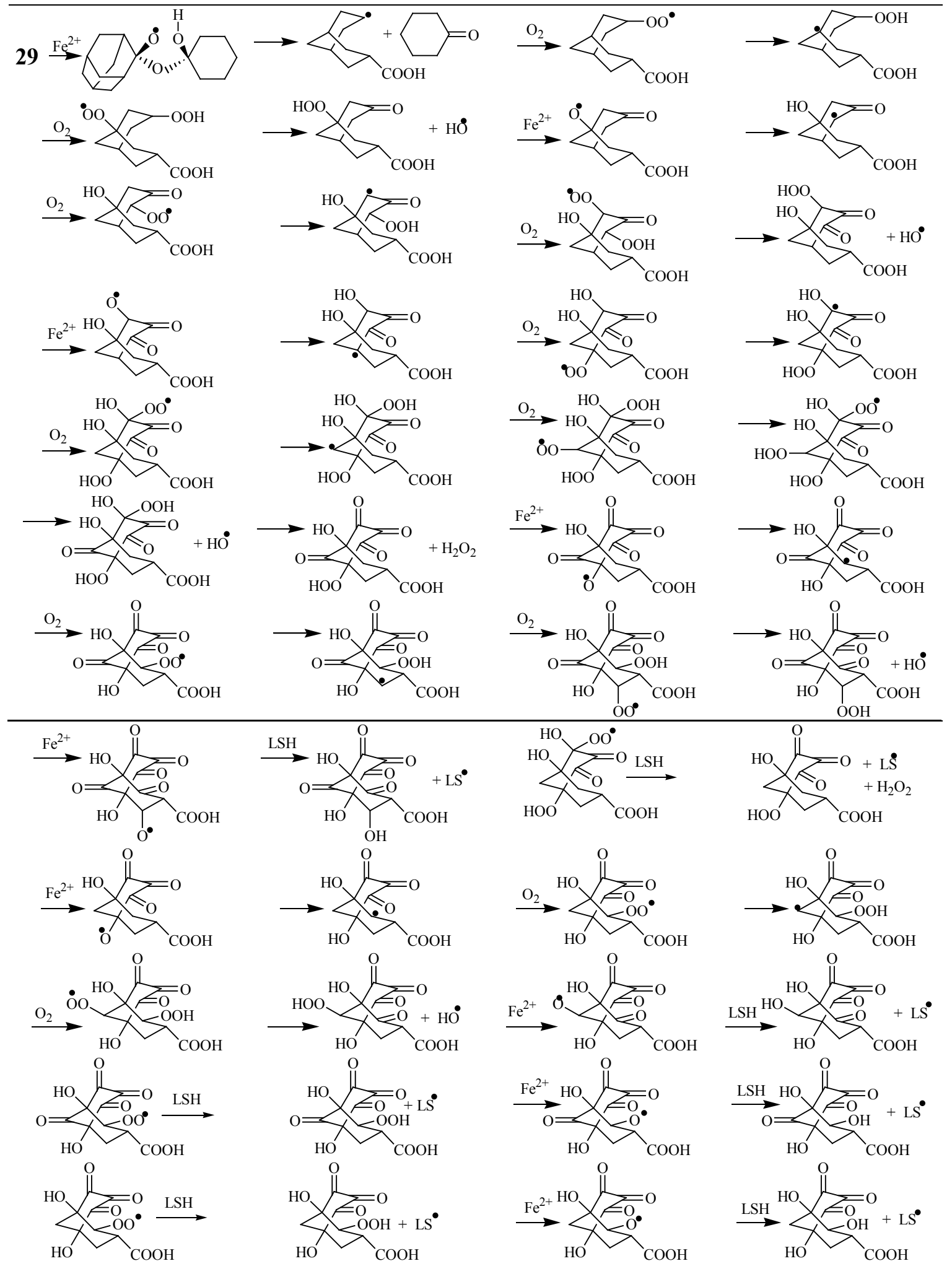

Scheme 3: The mechanism of 29 oxidation. ${ }^{46}$ 
Kinetic schemes of oxidation of compounds 37-46 are given by the example of compound 37 (Scheme 4).

The analysis of correlation between the therapeutic effect of compound $\mathbf{1}$ and its analogues 2-13 and the yield of hydroxyl radicals showed that
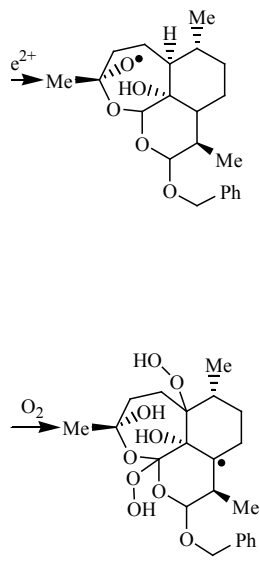

$\Delta H=29.2 ; E=49.3$

$k=2.8 \times 10^{4}$

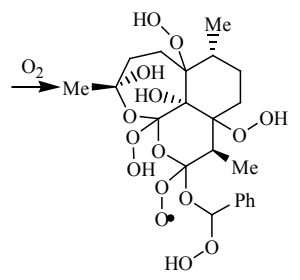

$\Delta H=0.0 ; E=21.9 ;$

$k=7.1 \times 10^{7}$

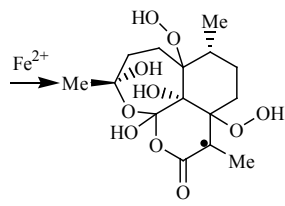

$\Delta H=-62.9 ; E=11.7$;

$k=4.3 \times 10^{10}$

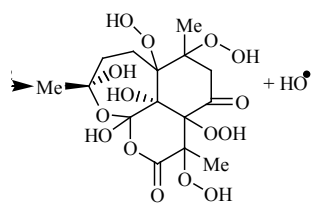

$\Delta H=-110.5 ; E=42.7$;

$$
k=6.8 \times 10^{4}
$$

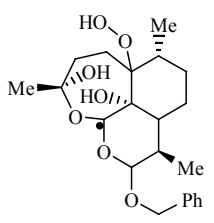

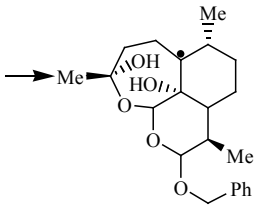

$\Delta H=-48.2 ; E=16.6$;

$$
k=6.3 \times 10^{9}
$$

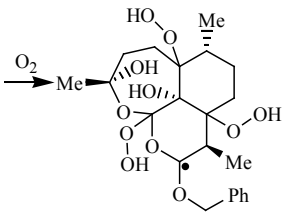

$$
\Delta H=27.4 ; E=48.3 ;
$$$$
k=4.0 \times 10^{4}
$$

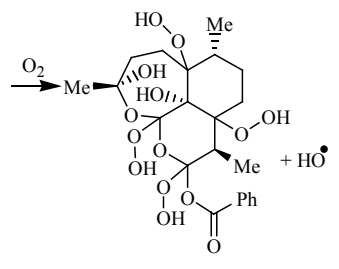

$$
\begin{gathered}
\Delta H=-122.8 ; E=44.2 ; \\
k=9.5 \times 10^{2}
\end{gathered}
$$

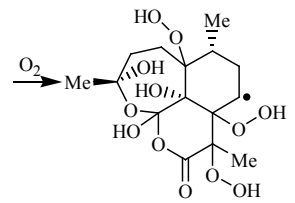

$$
\Delta H=45.9 ; E=57.6 \text {; }
$$$$
k=7.6 \times 10^{2}
$$
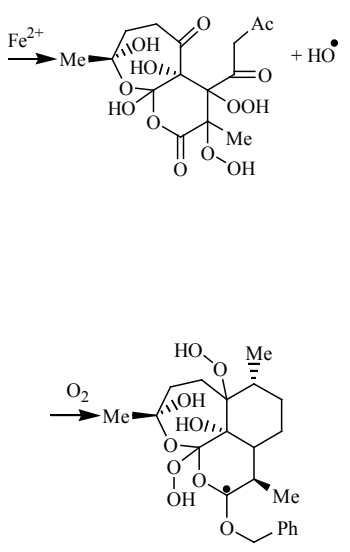

$$
\begin{gathered}
\Delta H=27.4 ; E=48.3 ; \\
k=4.0 \times 10^{4}
\end{gathered}
$$
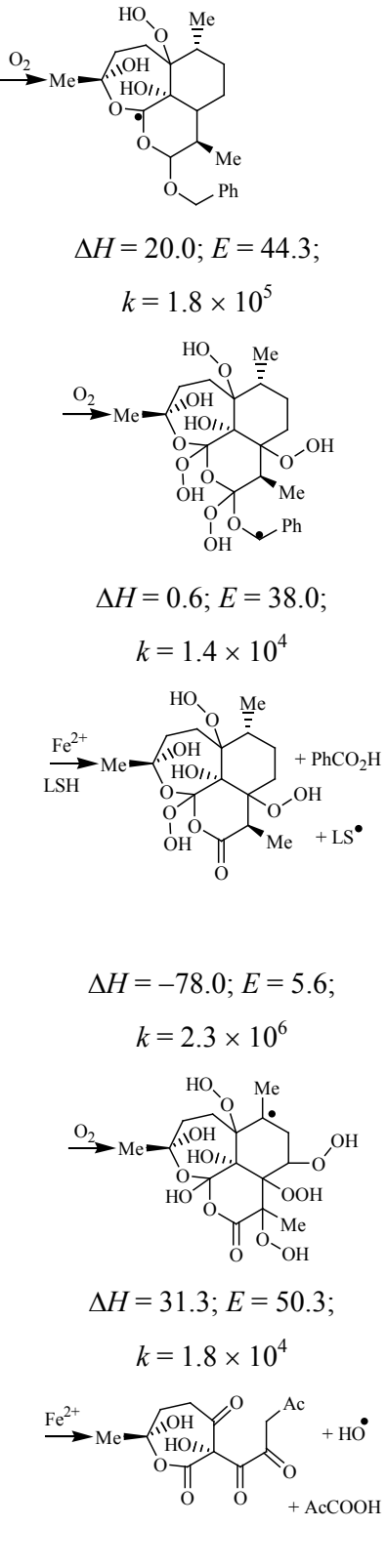

$\Delta H=20.0 ; E=44.3$;

$$
k=1.8 \times 10^{5}
$$

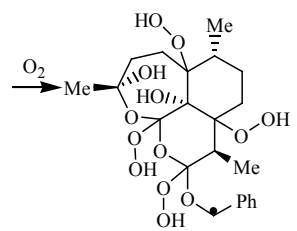

$$
\begin{gathered}
\Delta H=0.6 ; E=38.0 ; \\
k=1.4 \times 10^{4}
\end{gathered}
$$

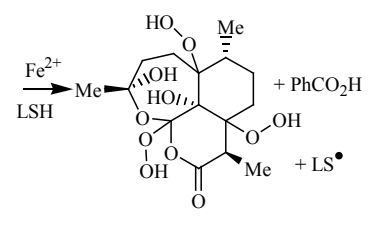

$$
\begin{gathered}
\Delta H=-78.0 ; E=5.6 ; \\
k=2.3 \times 10^{6}
\end{gathered}
$$
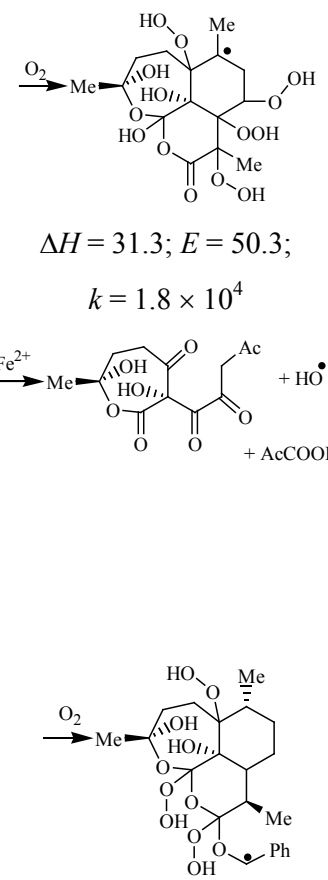

$$
\begin{gathered}
\Delta H=0.6 ; E=38.0 ; \\
k=1.4 \times 10^{4}
\end{gathered}
$$




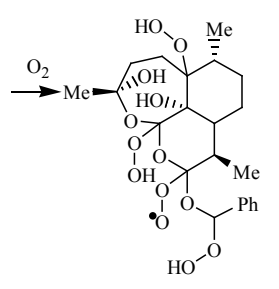

$\Delta H=0.0 ; E=21.9$

$$
k=7.1 \times 10^{7}
$$

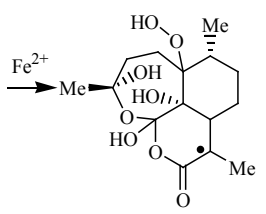

$$
\begin{gathered}
\Delta H=-62.9 ; E=11.7 ; \\
k=4.3 \times 10^{10}
\end{gathered}
$$

$$
\begin{gathered}
\Delta H=-110.5 ; E=42.7 ; \\
k=6.8 \times 10^{4}
\end{gathered}
$$

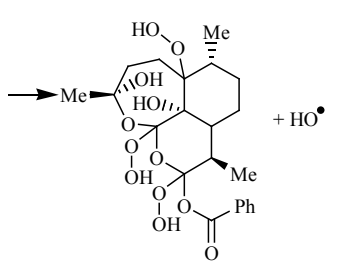

$\Delta H=-122.8 ; E=44.2$

$k=9.5 \times 10^{2}$

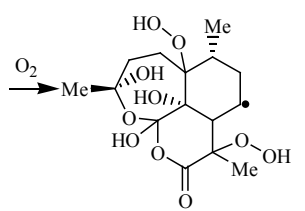

$\Delta H=45.9 ; E=57.6$

$k=7.6 \times 10^{2}$

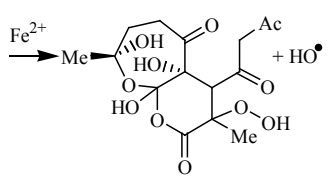

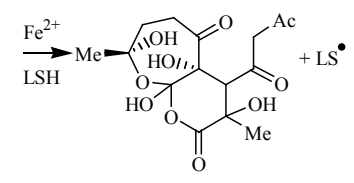

$$
\begin{gathered}
\Delta H=-78.5 ; E=5.8 ; \\
k=2.1 \times 10^{6}
\end{gathered}
$$

Scheme 4: The mechanism of 37 oxidation [48]; the values of enthalpies $(\Delta H, \mathrm{~kJ} / \mathrm{mol})$, activation energies $(E, \mathrm{~kJ} / \mathrm{mol})$ and rate constants $\left(k(310 \mathrm{~K}) \mathrm{s}^{-1}\right)$ were calculated by the method of intersecting parabolas [32-34].

the dependence of the $\mathrm{IC}_{50}$ value on the $n_{\mathrm{OH}}$ parameter is exponential (Equation 1) within the interval of $n_{\mathrm{OH}}$ from 2.5 to 4.0. The therapeutic effect of the generated hydroxyl radicals alone can be estimated using (Equation 1) on the basis of data given in (Table 2).

\begin{tabular}{|c|c|c|c|c|c|}
\hline Compound & $n_{\mathrm{OH}}$ & $n_{\mathrm{LS}}$ & $I C_{50}(i) / M(i)$ & $I C_{50}(1) M(\mathrm{i}) / I C_{50}(\mathrm{i}) M(1)$ & $\left\{I C_{50}(1) M(\mathrm{i}) / I C_{50}(\mathrm{i}) M(1)\right\}_{\mathrm{OH}}$ \\
\hline 1 & 3.17 & 1.17 & 12.5 & 1.00 & 1.00 \\
\hline 36 & 3.83 & 0.83 & 7.2 & 1.74 & 13.1 \\
\hline 37 & 3.42 & 1.69 & 8.2 & 1.52 & 2.65 \\
\hline 38 & 3.42 & 1.69 & 138.1 & 0.09 & 2.65 \\
\hline 39 & 3.42 & 1.69 & 6.3 & 1.98 & 2.65 \\
\hline 40 & 3.42 & 1.69 & 12.5 & 1.00 & 2.65 \\
\hline 41 & 3.42 & 1.69 & 3.8 & 3.30 & 2.65 \\
\hline 42 & 3.42 & 1.69 & 6.6 & 1.89 & 2.65 \\
\hline 43 & 3.42 & 1.69 & 4.3 & 2.91 & 2.65 \\
\hline 44 & 3.42 & 1.69 & 13.3 & 0.94 & 2.65 \\
\hline 45 & 3.42 & 1.69 & 22.5 & 0.55 & 2.65 \\
\hline 46 & 3.42 & 1.69 & 12.6 & 0.99 & 2.65 \\
\hline
\end{tabular}

The comparison of experimental and calculated values of $\mathrm{IC}_{50}$ for compounds 36-45 are presented on (Table 5). The last colon contains the values of relative activity of drug that is result of generation of $\mathrm{HO}^{*}$ only. They were calculated from the yield of hydroxyl radicals via Equation 1.

From data of Table 5 one can see that only compound $\mathbf{4 0}$ demonstrates activity higher than caused by generation of hydroxyl radicals. The activity of others are more than 1, but lower than induced by hydroxyl radicals only. Hence, the kinetic analysis of radical reactions, which result from the transformations of the hybrid antimalarial compounds, revealed the two ways of action, one being caused by the hydroxyl radicals alone and the other one, that does not involve radical generation.

Table 5: Comparison of the antimalarial activity of compound 1 and hybrid derivatives of 10-dihydroartemisinin (36 - 46) [47] with the number of hydroxyl radicals $n_{\mathrm{OH}}$, which are formed due to their intramolecular oxidation [48]. 


\section{Conclusion}

Thus, a kinetic analysis of intramolecular oxidation reactions of $\mathbf{1}$ derivatives in combination with the published data on antimalarial activity makes it possible to formulate the following mechanism of action of the peroxide drugs, analogs of compound $\mathbf{1}$. Under the reaction of the Fe(II) chelates the compound containing the peroxide group is transformed into the alkoxyl radical. This radical isomerizes to the alkyl radical, which further undergoes intramolecular chain oxidation. This oxidation results in polyatomic hydroperoxides, which, in turn, generates radicals in the reaction with $\mathrm{Fe}$ (II). The next cascade of radical reactions generates very reactive hydroxyl radicals, whose sources are peroxyl radicals with hydroperoxide fragments and $\alpha$-dihydroperoxides. The higher the yield of hydroxyl radicals $n_{\mathrm{OH}}$, the more efficient the drug. The dependence of the antimalarial activity of the $\mathrm{i}^{\text {th }}$ drug $\mathrm{IC}_{50}(\mathbf{1}) M(\mathrm{i}) / \mathrm{IC}_{50}(\mathrm{i}) M(\mathbf{1})$ on the yield of radicals $\mathrm{HO}{ }^{*} n_{\mathrm{OH}}$ is nonlinear (exponential). The compounds with $n_{\mathrm{OH}} \geq$ 3 are efficient.

The mechanism of the therapeutical activity of dispiro-1,2,4-trioxolanes containing a peroxide bridge is thus similar to that of $\mathbf{1}$ and its derivatives. Among the radicals formed by the oxidation of dispiro-1,2,4-trioxolanes, only hydroxyl radicals exhibit a unique antimalarial activity. They are formed from dispiro-1,2,4-trioxolanes, which generate cyclic alkyl radicals during the decomposition of alkoxyl radicals. The oxidation of the former radicals gives rise to secondary hydroperoxide groups, whose subsequent radical transformation generates hydroxyl radicals. This is possible only in the case of dispiro-1,2,4-trioxolanes with polycyclic substituents (compounds 29-32). Decyclization of primary alkoxyl radicals formed from monocyclic dispiro-1,2,4-trioxolanes results in the transformation of the latter into linear peroxyl radicals that reacts faster with the protein thio-groups. The generation of hydroxyl radicals thus becomes impossible.

The results of study the cyclohexyl endoperoxides supplement earlier data concerning free radical conversions of $\mathbf{1}$ and its derivatives. The antimalarial activity of the cyclohexyl endoperoxides is mainly determined by two factors. The major factor is generation of hydroxyl radicals by the polyatomic hydroperoxides that result from the chain intramolecular oxidation of the drug. The higher the HO' yield, the higher the antimalarial activity of the compound. The other, less significant factor is generation of other radicals $\left(\mathrm{RO}^{*}, \mathrm{RO}_{2}^{\cdot} \mathrm{LS}^{*}\right)$, which also kill the plasmodium, but do this less effectively. In terms of $\mathrm{IC}_{50}$, these radicals are 1-2 orders of magnitude less effective than the hydroxyl radical. The peroxides generating a single radical are practically inactive against the plasmodium.

The kinetic analysis of radical reactions, which result from the transformations of the hybrid peroxide antimalarial compounds revealed the two ways of action, one being caused by the hydroxyl radicals alone and the other one that does not involve radical generation. This method was used for differentiation of the way of therapeutic action for a series of ten model compounds, which were synthesized starting from 10-dihydroartemisinine. The therapeutic action of several compounds evidenced the additional effect of the substituent, and for the others the analysis revealed the ability of the corresponding substituents to decrease the therapeutic effect, which is caused by the generation of hydroxyl radicals.

\section{Acknowledgment}

We thank the Chemistry and Materials Sciences Department of the Russian Academy of Sciences for financial support of this work (grant no. 9, Medical and Biomolecular Chemistry Program of the Department of Chemistry and Materials Sciences, Russian Academy of Sciences).

\section{References}

1. Li Y, Huang H, Wu YL (2006) Qinghaosu (Artemisinin) - a fantastic Antimalarial Drug from a Traditional Chinese Medicine. In Medicinal Chemistry of Bioactive Natural Products. Eds Liang X T Fang W S New York J Wiley and Sons 183-256.

2. Meshnick SR, Taylor TE, Kamchonwongpaisan S (1996) Artemisinin and Antimalarial Endoperoxides: from Herbal Remedy to Targeted Chemotherapy. Microbiol Rev 60: 301-315.

3. Haynes RK (2001) Artemisinin and derivatives: the future for malaria treatment? Curr Opin Infect Dis 14: 719-726.

4. Borstnik K, Paik IH, Shapiro TA, Posner GH (2002) Antimalarial Chemotherapeutic Peroxides: Artemisinin, Yingzhaosu A and related Compounds. Int J Parasitol 32: 1661-1667.

5. Wu Y (2002) How Might Qinghaosu (Artemisinin) and Related Compounds Kill the Intraerythrocytic Malaria Parasite? A Chemist's View. Acc Chem Res 35: 255-259.

6. Robert A, Dechy-Cabaret O, Cazelles J, Meunier B (2002) From Mechanistic Studies on Artemisinin Derivatives to New Modular Antimalarial Drugs. Acc Chem Res 35: $167-174$

7. Eckstein-Ludwig U, Webb RJ, van Goethem IDA, East JM, Lee AG et al. (2003) Artemisinins Target the SERCA of Plasmodium Falciparum. Nature 424: 957-961.

8. Ridley RG (2003) Malaria: To kill a Parasite. Nature 424: 887-889.

9. Tang Y, Dong Y, Vennerstrom JL (2004) Synthetic Peroxides as Antimalarials. Med Res Rev 24: 425-448.

10. O Neill PM, Posner GH (2004) A Medicinal Chemistry Perspective on Artemisinin and Related Endoperoxides. J Med Chem 47: $2945-2964$.

11. Haynes RK, Krishna S (2004) Artemisinins: Activities and Actions. Microbes Infect 6: 1339-1346.

12. Posner GH, O Neill PM (2004) Knowledge of the Proposed Chemical Mechanism of Action and Cytochrome P450 Metabolism of Antimalarial Trioxanes Like Artemisinin Allows Rational Design of New Antimalarial Peroxides. Acc Chem Res 37: 397-404.

13. Namdeo A G, Mahadik K R, Kadam S S (2006) Antimalarial Drug - Artemisia annua. Pharmacognosy Magazine. 2: $106-111$.

14. Butler AR, Gilbert BC, Hulme P, Irvine LR, Renton L (1998) EPR Evidence for the Involvement of Free Radicals in the Iron-Catalysed Decomposition of Qinghaosu (Artemisinin) and Some Derivatives; Antimalarial Action of Some Polycyclic Endoperoxides. Free Radic Res 28: 471-476.

15. Wu WM, Wu Y, Wu YL, Yao ZJ, Zhou ChM et al. (1998) Unified Mechanistic Framework for the Fe(II)-Induced Cleavage of Qinghaosu and Derivatives/Analogues. The First Spin-Trapping Evidence for the Previously Postulated Secondary C-4 Radical. J Am Chem Soc 120: 3316-3325.

16. Meshnick SR (2002) Artemisinin: Mechanisms of Action, Resistance and Toxicity. Int J Parasitol 32: 1655-1660. 
Citation: Denisov ET, Denisova TG (2014) Hydroxyl Radical as Key Intermediate in Curing Action of Artemisinin and its Analogs. Med chem 4: 798813. doi:10.4172/2161-0444.1000233

17. O Neill PM, Bishop LPD, Searle NL, Maggs JL, Storr RC et al. (2000) Biomimetic Fe(II)-Mediated Degradation of Arteflene (Ro-42-1611). The First EPR Spin-Trapping Evidence for the Previously Postulated Secondary Carbon-Centered Cyclohexyl Radical. J Org Chem 65: 1578-1582.

18. Wang DY, Wu YL (2000) A possible Antimalarial Action Mode of Qinghaosu (Artemisinin) Series Compounds. Alkylation of Reduced Glutatione by C-centered primary Radicals Produced from Antimalarial Compound Qinghaosu and 12-(2,4-dimethoxyphenyl)-12-deoxoqinghaosu. Chem Commun 2193-2194.

19. Berman PA, Adams PA (1997) Artemisinin Enhances Heme-Catalysed Oxidation of Lipid Membranes. Free Radic Biol Med 22: $1283-1288$.

20. Wang DY, Wu YL, Wu Y, Liang J, Li Y (2001) Further Evidence for the Participation of Primary Carbon-Centered Free Radicals in the Antimalarial Action of the Qinghaosu (Artemisinin) Series of Compounds. J Chem Soc Perkin Trans 1: 605-609.

21. Denisov E, Denisova T, Ismail F (2005) Intramolecular Reaction of Free Radicals Formed from Artemisinin. Int J Chem Kinet 37: $554-565$.

22. Solodova SL, Denisov ET (2006) Competition between Mono- and Bimolecular Reactions of Artemisinin alkoxyl Radicals. Russian Chemical Bulletin 55: 1557-1565.

23. Solodova SL, Denisov ET (2007) Competition of Monomolecular and Bimolecular Reactions of the Alkyl Radicals of Artemisinin. Kinetics and Catalysis 48: 204-213.

24. Solodova SL, Denisov ET, Denisova TG (2008) Artemisinin as a Self-propagating Radical Initiator ander Aerobic Conditions. Mendeleev Commun 18: 24-26.

25. Solodova SL, Denisov ET (2008) Intramolecular Chain Reaction of Artemisinin Oxidation. Russian Chemical Bulletin 57: $274-282$.

26. Solodova SL, Denisov ET (2009) Reactions of Alkoxy and Peroxy Radicals formed upon the Decomposition of Hydroxyperoxide Groups in the Artemisinin Derivatives Russ Chem Bull 58: 777-785.

27. Denisov ET, Solodova SL, Denisova TG (2010) Radical Chemistry of Artemisinin. Russ Chem Rev 79: 981-1003.

28. Denisov ET (2011) An Important Role of Intramolecular Free Radical Reactions in Antimalarial Activity of Artemisinin and its Analogs. Org Biomol Chem 9: $4219-4225$.

29. Denisov ET, Denisova TG (2010) Generation of Hydroxyl Radicals by the Intramolecular Oxidation of Tricyclic Artemisinin Analogs and their Antimalarial Activity. Russ Chem Bull 59: 1881-1889.

30. Denisov ET, Denisova TG (2011) Hydroxyl Mechanism of the Antimalarial Effect of Artemisinin and its Analogs. Russ Chem Bull 60: $1421-1435$.

31. Denisov E T, Denisova T G (2010) Generirovaniye HO• kak Klyuchevaya Stadiya Protivomalyariynogo Deystviya Analogov Artemisinina [The Generation of HO• as a Key Stage of Antimalarial Action of Analogs of Artemisinin]. Butlerov Soobshch. Butlerov's Reports 23: 11-22.

32. Denisov ET, Afanas'ev IB (2005) Oxidation and Antioxidants in Organic Chemistry and Biology. Boca Raton FI CRC Press Taylor and Francis Group.

33. Denisov ET (1997) New Empirical Models of Radical Abstraction Reactions. Russ Chem Rev 66: 859-876.

34. Denisov E (1999) Models for Abstraction Addition Reactions of Free Radicals. In General Aspects of the Chemistry of Radicals. Ed. Alfassi, Z. B. Chichester: J. Wiley and Sons $79-137$.

35. Creek DJ, Charman WN, Chiu FCK, Prankerd RJ, Dong Y et al. (2008) Relationship between Antimalarial Activity and Heme Alkylation for Spiro- and Dispiro-1,2,4trioxolane Antimalarials. Antimicrob Agents Chemother 52: 1291-1296.

36. Avery MA, Gao F, Chong WKM, Hendrickson TF, Inman WD et al. (1994) Synthesis, Conformational Analysis, and Antimalarial Activity of Tricyclic Analogs of Artemisinin. Tetrahedron 50: 957-972.

37. Posner G H, Wang D, Cumming J N, Oh C H, French A N et al. (1995) Further Evidence Supporting the Importance of and the Restrictions on a Carbon-Centered Radical for High Antimalarial Activity of 1,2,4-Trioxanes Like Artemisinin. J Med Chem 38: 2273-2275.

38. Denisov E T, Denisova T G (2013) Hydroxyl Mechanism of the Antimalarial Action of Dimeric Analogues of Artemisinin. Kinetics and Catalysis 54: 1-13.

39. Luo YR (2003) Handbook of Bond Dissociation Energies in Organic Compounds. Boca Raton FI CRC Press.

40. Buxton G V, Greenstock C L, Helman W P, Ross A B (1988) Critical Review of Rate Constants for Reactions of Hydrated Electrons, Hydrogen Atoms and Hydroxyl Radicals $\left(\cdot \mathrm{OH} / \bullet^{-}\right)$in Aqueous Solution. J Phys Chem Ref Data 17: 513-817.

41. Wu YL, Chen HB, Jiang K, Li Y, Shan F et al. (2009) Interaction of Biomolecules with Qinghaosu (Artemisinin) and its Derivatives in the Presence of Ferrous lon - an Exploration of Antimalarial Mechanism. Pure and Applied Chemistry 71: 1139-1142.

42. Wu WM, Yao ZJ, Wu YL, Jiang K, Wang YF et al. (1996) Ferrous lon Induced Cleavage of the Peroxy Bond in Qinghaosu and its Derivatives and the DNA Damage associated with this Process. Chem Commun 18: 2213-2214.

43. Crespo MP, Avery TD, Hanssen E, Fox E, Robinson TV et al. (2008) Artemisinin and a Series of Novel Endoperoxide Antimalarials Exert Early Effects on Digestive Vacuole Morphology. Antimicrob Agents Chemother 52: 98-109.

44. Denisov ET, Denisova TG (2012) Free-Radical Generation Mechanism and Antimalarial Activity of Cyclohexyl Endoperoxides. Kinetics and Catalysis 53: $172-181$.

45. Creek DJ, Charman WN, Chiu FCK, Prankerd RJ, McCullouch KJ et al. (2007) Iron-mediated Degradation Kinetics of Substituted Dispiro-1,2,4-trioxolane Antimalarials. J Pharm Sci 96: 2945-2956.

46. Denisov ET, Denisova TG (2013) Generation of Radicals and Antimalarial Activity of Dispiro-1,2,4-trioxolanes. Russ J Phys Chem A 87: 10-19.

47. Hindley S, Ward SA, Storr RC, Searle NL, Bray PG et al. (2002) Mechanism-Based Design of Parasite-Targeted Artemisinin Derivatives: Synthesis and Antimalarial Activity of New Diamine Containing Analogues. J Med Chem 45: 1052-1063.

48. Denisov ET, Denisova TG (2013) Mechanism of Hydroxyl Radical Induced Antimalarial Action of Hybrid Analogues of 10-Dihydroartemisinin. Russian Chemical Bulletin 62: $2579-2589$. 